\title{
A Modified Step-Up Converter with Small Signal Analysis-Based Controller for Renewable Resource Applications
}

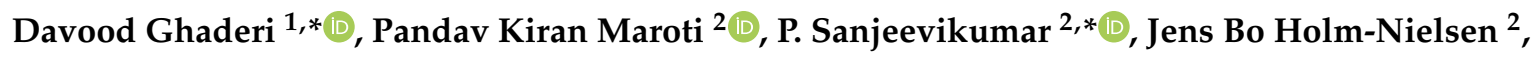 \\ Eklas Hossain ${ }^{3}(D)$ and Anand Nayyar ${ }^{4}$ (D) \\ 1 Electrical and Electronics Engineering Department, Bursa Technical University, 16310 Bursa, Turkey \\ 2 Center for Bioenergy and Green Engineering, Department of Energy Technology, Aalborg University, \\ 6700 Esbjerg, Denmark; kiranpandav88@yahoo.co.in (P.K.M.); jhn@et.aau.dk (J.B.H.-N.) \\ 3 Oregon Renewable Energy Center (OREC), Department of Electrical Engineering and Renewable Energy, \\ Oregon Tech, Klamath Falls, OR 97601, USA; eklas.hossain@oit.edu \\ 4 Graduate School, Duy Tan University, 254 Nguyen Van Linh, Danang 550000, Vietnam; \\ anandnayyar@duytan.edu.vn \\ * Correspondence: davood.ghaderi@btu.edu.tr (D.G.); san@et.aau.dk (P.S.)
}

Received: 20 November 2019; Accepted: 15 December 2019; Published: 20 December 2019

\begin{abstract}
Solar energy is one of the most important renewable sources due to its advantages such as simple structure, convenient installation, diverse applications, and low maintenance costs. Low power generation is the main concern with solar panels, so the maximum transmission of this power is a prime priority. The design of boost converters with the ability to generate high voltage gain, efficient structure, and stable and low-cost control circuits is the first step after installing these panels. This study presents a simple and high-gain design of a step-up converter, which uses only one power switch. The significance of this issue is when it will be apparent to know that each switch needs a separate control circuit and complex systems require more control topologies. In comparison with the conventional converter, the gain of the proposed converter, with the use of two additional diodes, a capacitor, and an inductor, was five times greater than the gain of a classical converter with $80 \%$ of the duty cycle. The proposed converter can solve the narrow turn-off period problem for the power semiconductor components in order to achieve higher DC voltages that are possible at higher duty cycles in classical converters. Small signal analysis of the proposed converter is presented and a controller based on steady-space matrixes is presented. The reaction of the proposed controller is considerable since a deep mathematical analysis supports this controller. The principal operations of the proposed converter and the projected controller were analyzed mathematically and verified with the help of MATLAB/SIMULINK. Additionally, hardware implementation of the proposed converter was done on a laboratory-scale around $100 \mathrm{~W}$.
\end{abstract}

Keywords: step-up converter; renewable energy sources; high voltage gain converter

\section{Introduction}

The optimal use of diverse renewable energy sources is one of the main challenges in terms of power and energy. In order to connect renewable energy sources (RESs) to the network, the use of electronic power interfaces is essential. Solar cell systems are one of the most desirable renewable energy sources due to the availability of solar radiation and flexibility in installing panels. It is preferable to use modular photovoltaic systems to increase the efficiency of these panels and to overcome problems such as shadowing on panels and mismatches between them [1,2]. In these systems, a high-efficiency DC-DC converter is used to increase the output voltage of the photovoltaic cells and connect them 
into the high-voltage bus [3-6]. Additionally, these batches are used in many applications including emergency electrical systems, fuel cells, server power supplies, and high-intensity discharge lamps [7].

Boost converters can be divided into isolated and non-isolated categories. Isolated converters can usually present low amounts of efficiency. In these types of choppers, the high voltage gain is obtained through adjustment of the correct transformer ratio. Non-isolated converters are highly applicable structures due to their high efficiency, high power density, and low cost in medium and low power systems [8]. In [9], a three-level boost converter was introduced. This converter can reduce the voltage stress of semiconductor components when compared to a conventional boost converter, which is suitable for high voltage applications. As a result, switching losses and electromagnetic interference (EMI) are improved due to low voltage stress in this configuration. Nevertheless, semiconductor parts act under hard switching conditions and the problem of recovering the output diode is one of the most serious problems in this type of converter.

In $[10,11]$, a highly addictive coupled-inductor single-switch converter was introduced. In [10], the leakage energy of the coupled-inductors was reclaimed by the clamp circuit, which reduces the voltage stress on the switch and diodes. As a result, the switch can be used with a low light-up time resistance, which results in improved efficiency. However, it should be noted that this converter has a complex structure. In [12], an interleaved based configuration by coupled-inductors was introduced. Due to the use of a voltage multiplier and coupled-inductors, a high voltage gain was achieved for the proposed structure. In this converter, due to the use of cross-linked inductors, the input current ripple decreased. Additionally, by using active clamping circuits, the leakage energy of the inductor's spools and soft-switching conditions were created for the main switches. One of the disadvantages of topologies by coupled-inductor is the high voltage stresses on output diodes that make use of high voltage diode applications and clamper structures. In [13], a high-gain nonsymmetrical interleaved converter was presented. In this structure, two ferrite cores were used for two inductors. Due to the use of two switches, in addition to reducing the current stress of the switches, the ripple of the input current will be limited. One of the disadvantages of this converter is the creation of hard switching conditions, which increases the number of magnetic elements and the total volume of the circuit.

In [14], a boost converter integrated with a fly-back topology was introduced to obtain the high voltage gain. In this structure, the boost converter acts like a passive clamp circuit and recycles the leakage energy. In [15], a similar boost converter was introduced. In this converter, the clamper capacitor is located in the direction of charging the output capacitor, and in addition to absorbing the self-leakage energy, it also increases the voltage gain of the converter. To reduce the number of components, single switch fly-back boost converters are commonly integrated. Different designs of this converter are presented in [16]. One of the main concerns is the voltage and current spikes on the switching devices in a power module. Zero voltage switching (ZVS), zero current switching (ZCS), zero voltage transition (ZVT), and zero current transition (ZCT) are different approaches that can reduce these stresses and decrease the switching losses on power diodes and power switches $[17,18]$. In these ways, to obtain higher efficiency, applying an additional switch is often inevitable and can need more control topologies and enhance the complexity and cost of the converter.

Cascade structures can be employed for high step-up requirements. The authors in $[19,20]$ proposed sample topologies for this kind of converter. Higher DC gains can be achieved by applying more serial blocks of converters, but by increasing the number of blocks, the number of components will increase, especially extra power switches that have been applied, and the dynamic and frequency losses will increase, which will seriously affect the efficiency. Furthermore, the control process will be difficult for more power switches and the total cost will increase. Our study introduces a topology that can provide a pre-amplifier block containing an inductor, two power diodes, and a capacitor. This configuration can increase the input voltage, and according to the duty ratio, this amount can be greater. Next, it acts as a boost converter and increases the voltage to higher values. For high efficiency purposes, the diodes on the pre-amplifier part act in a complementary manner and when one of them is in ON mode, another is in OFF mode and vice versa. So, in comparison with a classical 
cascaded boost converter, the proposed configuration is more efficient. All mathematical analysis of the projected converter, calculations of the voltage gain, and the controller design and small signal analysis based on steady space matrixes are presented in Section 2. Section 3 presents the simulation results and the implemented prototype and the performance assessment of the proposed simple controller is presented in Section 4.

\section{Modified Boost Converter (MBC)}

Figure 1a-c shows the conventional, cascaded, and proposed boost converters, respectively. As can be seen in Figure 1c, a boosting structure is located between the entrance inductor and the power switch. Based on switch ON or OFF working modes, only one of the $D_{1}$ and $D_{2}$ diodes will be active in the structure and in this way, it makes a preamplifier layer for boosting purposes. All working principles and mathematical analyses have been stipulated for both ON and OFF states of the power switch.

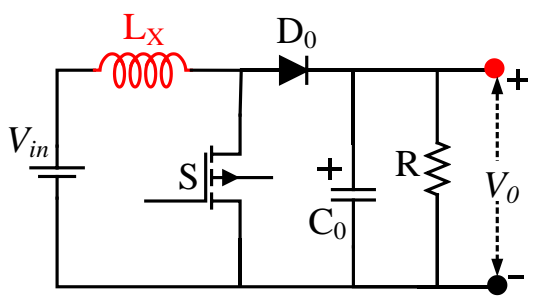

(a)

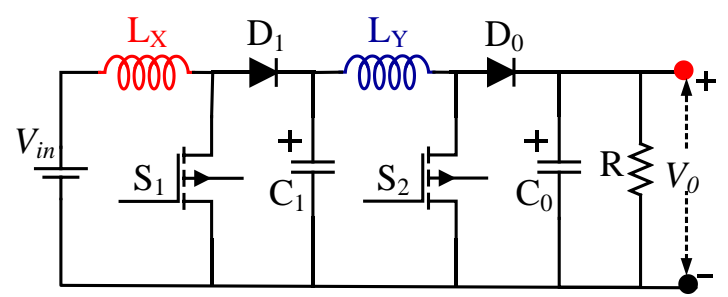

(b)

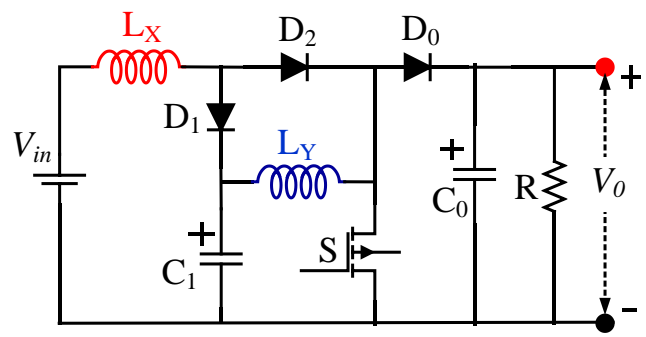

(c)

Figure 1. (a) Conventional; (b) cascaded; and (c) modified boost structures.

Figure 2 presents the Pulse Width Modulation (PWM) wave applied to the power switch in the boost converter. In this figure for the $\left[0, t_{1}\right]$ and $\left[t_{1}, T_{S}\right]$ time intervals switch $S_{1}$ is in ON and OFF modes, respectively. So, if we consider $\left[0, t_{1}\right]$ interval as $D_{S}$, the $\left[t_{1}, T_{S}\right]$ interval will be (1-D) $T_{S}$. In other words, $\mathrm{D}$ is the duty cycle of power switch $\mathrm{S}_{1}$.

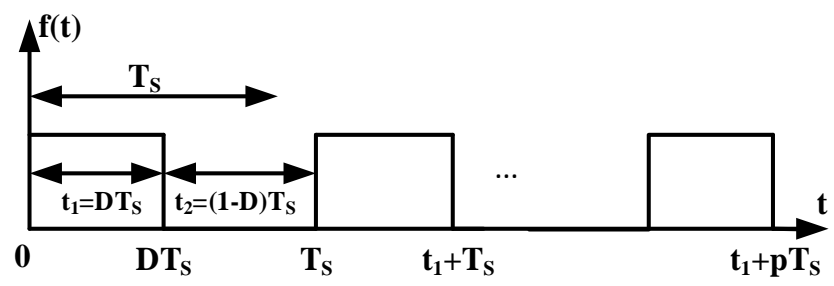

Figure 2. Pulse width modulation (PWM), which is applied to the power switch. Per period (T) contains two $\left(0, t_{1}\right)$ and $\left(t_{1}, T\right)$ intervals.

\subsection{Converter Analysis}

This part presents the converter's reactions for the ON and OFF time intervals. 


\subsubsection{Mode-I}

For a time-interval that the power switch receives the pulse and is in the short circuit state, both $L_{X}$ and $L_{Y}$ are magnetizing. This is done by inputting the voltage through diode $D_{2}$ and the power switch for $L_{X}$ and from $C_{1}$ and switch for $L_{Y}$. As can be seen in this mode, $D_{1}$ is in mode-I. Based on this statement, currents of inductors are rising in the $\mathrm{ON}$ state. As predicted, the voltage value on capacitor $C_{1}$ is discharging on $L_{Y}$ through the power switch and decreases. Additionally, the voltage on the output capacitor is discharging on the output load in this mode. The current value of diode $D_{1}$ is zero and because of the conducting condition for diode $D_{2}$, its current will increase. Figure 3a shows the ON state of the power switch in the projected structure and Figure $3 \mathrm{~b}$ illustrates the simplified form of Figure 3a.

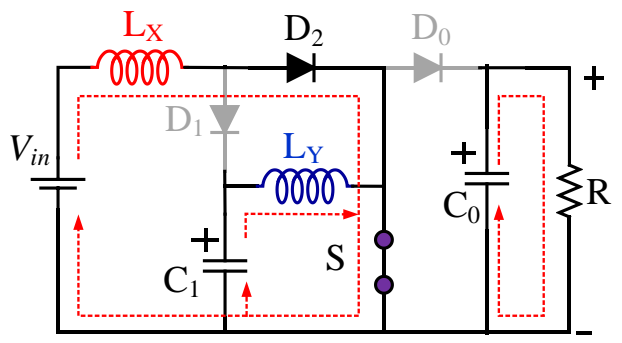

(a)

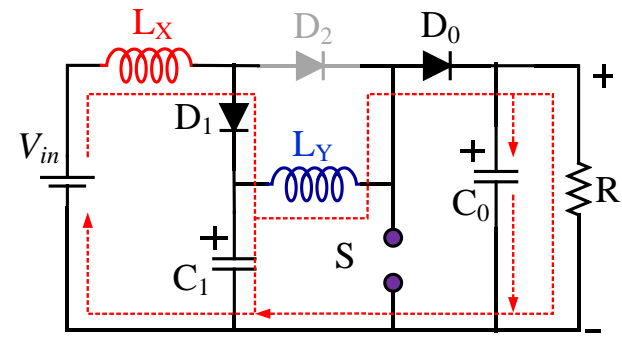

(b)

Figure 3. State of the proposed structure (a) when the power switch is $\mathrm{ON}$ and (b) when the power switch is OFF.

Based on these situations, the current waveform passing through inductor $L_{X}$ can be written as below:

$$
L_{X} \frac{d i_{L X}}{d t}=V_{\text {in }} \Rightarrow \frac{d i_{L X}}{d t}=\frac{V_{\text {in }}}{L_{X}}
$$

The current of inductor $L_{Y}$ is:

$$
L_{Y} \frac{d i_{L Y}}{d t}=v_{C 1} \Rightarrow \frac{d i_{L Y}}{d t}=\frac{v_{C 1}}{L_{Y}}
$$

The voltage waveform for capacitor $C_{1}$ can be gained as:

$$
C_{1} \frac{d v_{C 1}}{d t}=-i_{L Y} \Rightarrow \frac{d v_{C 1}}{d t}=-\frac{i_{L Y}}{C_{1}}
$$

Finally, we can find the voltage for the output capacitor as Equation (4):

$$
C_{2} \frac{d v_{0}}{d t}=-\frac{v_{0}}{R} \Rightarrow \frac{d v_{0}}{d t}=-\frac{v_{0}}{C_{2} R}
$$

The steady-space matrix of the ON state for the proposed converter can be obtained by Equation (5)

$$
\left\{\begin{array}{l}
L_{X} \frac{d i_{L X}}{d t}=V_{i n}(d) \Rightarrow \frac{d i_{L X}}{d t}=\frac{V_{i n}}{L_{X}}(d) \\
L_{Y} \frac{d i_{L Y}}{d t}=v_{C 1}(d) \Rightarrow \frac{d i_{L Y}}{d t}=\frac{v_{C 1}}{L_{Y}}(d) \\
C_{1} \frac{d v_{C 1}}{d t}=-i_{L Y}(d) \Rightarrow \frac{d v_{C 1}}{d t}=\frac{-i_{L Y}}{C_{1}}(d) \\
C_{2} \frac{d v_{0}}{d t}=-\frac{v_{o}}{R}(d) \Rightarrow \frac{d v_{0}}{d t}=-\frac{v_{0}}{R C_{2}}(d)
\end{array}\right\} \Rightarrow\left[\begin{array}{c}
\dot{i_{L X}} \\
\dot{i_{L Y}} \\
\dot{c}_{C 1} \\
\dot{v}_{01}
\end{array}\right]=\left[\begin{array}{llll}
0 & 0 & 0 & 0 \\
0 & 0 & \frac{1}{L_{Y}} & 0 \\
0 & -\frac{1}{C_{1}} & 0 & 0 \\
0 & 0 & 0 & -\frac{1}{R C_{2}}
\end{array}\right]\left[\begin{array}{l}
i_{L X} \\
i_{L Y} \\
v_{C 1} \\
v_{01}
\end{array}\right]+\left[\begin{array}{l}
\frac{1}{L_{X}} \\
0 \\
0 \\
0
\end{array}\right]\left[V_{i n}\right]
$$

\subsubsection{Mode-II}

In this time interval, $L_{X}$ is demagnetizing on capacitor $C_{1}$ through $D_{1}$ and $D_{2}$ is in OFF mode. Additionally, inductor $L_{Y}$ is demagnetizing through diode $D_{0}$ on the output capacitor and load. In this 
time interval, as above-mentioned, the voltage values on capacitors $C_{1}$ and $C_{2}$ will increase through $L_{X}$ and $L_{Y}$, respectively. Figure 4 illustrates all of the components' conductions in both ON and OFF modes of power Metal Oxide Semiconductor Field Effect Transistor (MOSFET). Small signal analysis for this state was also analyzed and written below. Inductor $L_{X}$ can be calculated as:

$$
L_{X} \frac{d i_{L X}}{d t}=\left(V_{\text {in }}-V_{C 1}\right)(1-d) \Rightarrow \frac{d i_{L X}}{d t}=\frac{V_{\text {in }}-V_{C 1}}{L_{X}}(1-d)
$$

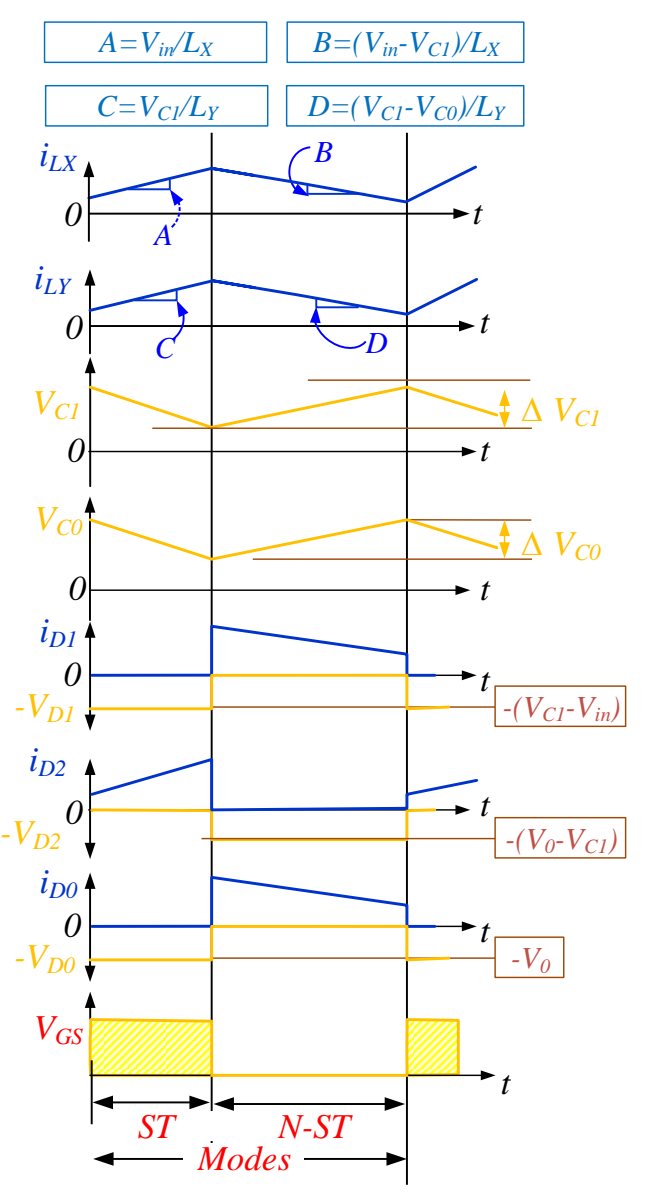

Figure 4. Mode of operation of the proposed structure.

Additionally, the current waveform of inductor $L_{Y}$ is equal with:

$$
L_{Y} \frac{d i_{L Y}}{d t}=\left(V_{C 1}-V_{0}\right)(1-d) \Rightarrow \frac{d i_{L Y}}{d t}=\frac{V_{C 1}-V_{0}}{L_{Y}}(1-d)
$$

The voltage waveform for capacitor $C_{1}$ and $C_{0}$ are:

$$
\begin{gathered}
C_{1} \frac{d v_{C 1}}{d t}=\left(i_{L X}-i_{L Y}\right)(1-d) \Rightarrow \frac{d v_{C 1}}{d t}=\frac{i_{L X}-i_{L Y}}{C_{1}}(1-d) \\
C_{0} \frac{d v_{0}}{d t}=\left(i_{L Y}-\frac{V_{0}}{R}\right)(1-d) \Rightarrow \frac{d v_{0}}{d t}=\frac{i_{L Y}-\frac{V_{0}}{R}}{C_{0}}(1-d)
\end{gathered}
$$


Term $(1-d)$ in the above equations guarantees work in the OFF state. Through the same method, we can obtain the below matrix for the OFF state of the power switch:

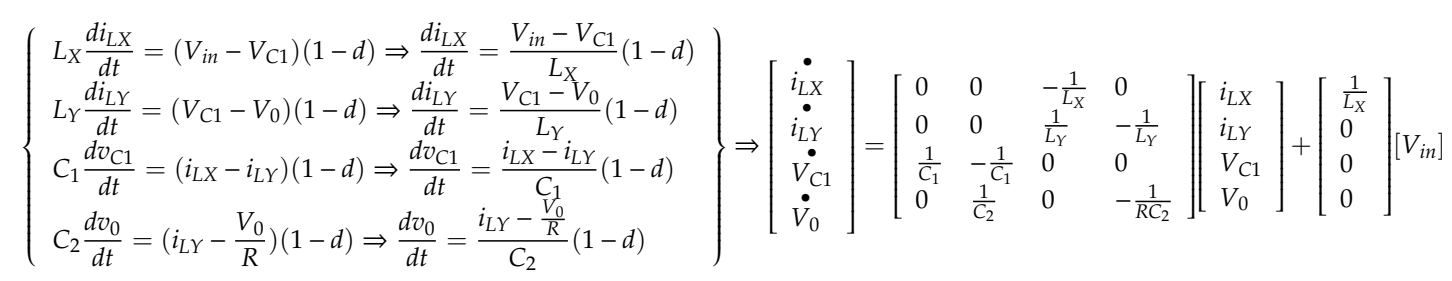

So, for both ON and OFF states of the switch, by adding Equations (5) and (10), we have:

$$
\left\{\begin{array}{l}
\frac{d i_{L X}}{d t}=-\frac{(1-d)}{L_{1}} V_{C 1}+\frac{1}{L_{X}} V_{i n} \\
\frac{d i_{L Y}}{d t}=\frac{1}{L_{Y}} V_{C 1}-\frac{(1-d)}{L_{Y}} V_{0} \\
\frac{d V_{C 1}}{d t}=\frac{(1-d)}{C_{1}} i_{L X}-\frac{1}{C_{1}} i_{L Y} \\
\frac{d V_{0}}{d t}=\frac{(1-d)}{C_{2}} i_{L Y}-\frac{1}{R C_{2}} V_{0}
\end{array}\right\} \Rightarrow\left[\begin{array}{l}
\dot{i_{L X}} \\
\dot{i_{L Y}} \\
\dot{V_{C 1}} \\
\dot{V_{0}}
\end{array}\right]=\left[\begin{array}{llll}
0 & 0 & -\frac{1-d}{L_{X}} & 0 \\
0 & 0 & \frac{1}{L_{Y}} & -\frac{1-d}{L_{Y}} \\
\frac{1-d}{C_{1}} & -\frac{1}{C_{1}} & 0 & 0 \\
0 & \frac{1-d}{C_{2}} & 0 & -\frac{1}{R C_{2}}
\end{array}\right]\left[\begin{array}{l}
i_{L X} \\
i_{L Y} \\
V_{C 1} \\
V_{0}
\end{array}\right]+\left[\begin{array}{l}
\frac{1}{L_{X}} \\
0 \\
0 \\
0
\end{array}\right]\left[V_{i n}\right]
$$

For the modeling process of a power circuit by the steady space method, we can find the relation between inputs, outputs, and the current and voltage derivations for the inductors and capacitors by Equation (12):

$$
Y=C X+D u
$$

where $X$ is the inductor current or capacitor voltage derivate matrix and $C$ is the coefficient matrix; $u$ is the input sources matrix; and $D$ is the coefficient matrix of $u$. While $Y$ as the output wave, can be obtained as:

$$
Y=V_{0}=\left[\begin{array}{llll}
0 & 0 & 0 & 1
\end{array}\right]\left[\begin{array}{c}
i_{L X} \\
i_{L Y} \\
V_{C 1} \\
V_{0}
\end{array}\right]
$$

The general view in order to obtain the small signal for the proposed converter can be re-the organized by Equation (14), since $A, B, C$, and $D$ can be introduced for the ON and OFF states of power switch:

$$
\begin{aligned}
& \hat{\dot{X}}=A \hat{X}+B \hat{u}+\left[\left(A_{1}-A_{2}\right) X+\left(B_{1}-B_{2}\right) u\right] \hat{d} ; \\
& \left\{\begin{array}{l}
A=A_{1} d+A_{2}(1-d) \\
B=B_{1} d+B_{2}(1-d) \\
C=C_{1} d+C_{2}(1-d) \\
D=D_{1} d+D_{2}(1-d)
\end{array}\right.
\end{aligned}
$$

If we want to introduce the general equation for both $\mathrm{ON}$ and OFF states of the power switch through Equation (14), we can obtain:

$$
\left[\begin{array}{c}
\hat{\dot{i_{L X}}} \\
\hat{\dot{i_{L Y}}} \\
\hat{\dot{V}} \\
V_{C 1} \\
\hat{V_{0}}
\end{array}\right]=\left[\begin{array}{cccc}
0 & 0 & -\frac{1-d}{L_{X}} & 0 \\
0 & 0 & \frac{1}{L_{Y}} & -\frac{1-d}{L_{Y}} \\
\frac{1-d}{C_{1}} & -\frac{1}{C_{d}} & 0 & 0 \\
0 & \frac{1-d}{C_{2}} & 0 & -\frac{1}{R C_{2}}
\end{array}\right]\left[\begin{array}{c}
\hat{i_{L X}} \\
\hat{i_{L Y}} \\
\hat{V_{C 1}} \\
\hat{V}_{0}
\end{array}\right]+\left[\begin{array}{c}
\frac{1}{L_{X}} \\
0 \\
0 \\
0
\end{array}\right]\left[\hat{V_{i n}}\right]+\left[\begin{array}{c}
\frac{V_{C 1}}{L_{X}} \\
\frac{V_{0}}{L_{Y}} \\
\frac{I_{L X}}{C_{1}} \\
\frac{I_{L Y}}{C_{2}}
\end{array}\right] \hat{d}
$$


So, in this condition, the output voltage of the structure can be gained by Equation (16):

$$
Y=\hat{V}_{0}=\left[\begin{array}{llll}
0 & 0 & 0 & 1
\end{array}\right]\left[\begin{array}{c}
\wedge \\
i_{L X} \\
\hat{i_{L Y}} \\
\hat{V_{C 1}} \\
\hat{V_{0}}
\end{array}\right]
$$

The voltage gain of the converter can be found through Equation (17):

$$
\frac{V_{0}}{V_{\text {in }}}=-\frac{\frac{(1-d)^{2}}{C_{1} C_{0} L_{X} L_{Y}}}{S^{4}+S^{3}\left(\frac{1}{R C_{2}}\right)+S^{2}\left(\frac{(1-d)^{2}\left(C_{1} L_{X}+C_{0} L_{Y}\right)+L_{X} C_{0}}{C_{1} C_{0} L_{X} L_{Y}}\right)+S\left(\frac{L_{Y}(1-d)^{2}+L_{X}}{C_{1} C_{0} L_{X} L_{Y}}\right)+\frac{(1-d)^{4}}{C_{1} C_{0} L_{X} L_{Y}}}
$$

\subsection{Design of Closed-Loop Controller}

By considering that the output voltage of a boost converter should be kept constant by the load or input voltage changes, the key point for controller design is finding an equation between the output voltage and one of the inductor currents or capacitor voltage derivatives and it can be obtained from Equation (9):

$$
C_{0} \frac{d V_{0}}{d t}+\frac{1}{R} V_{0}=(1-d) i_{L Y}=u ; C_{2} S V_{0}+\frac{1}{R} V_{0}=V_{0}\left(C_{0} S+\frac{1}{R}\right)=(1-d) i_{L Y}=u
$$

Other obtained equations cannot present a direct mathematical relation for the output voltage and Equation (9) is more suitable. Here, the final destination is generating a PWM signal for the power switch that will change according to these amendments to guarantee a fixed output voltage. In Equation (18), $\mathrm{u}$ is the PI controller output signal and $\mathrm{d}$ is the duty cycle of PWM, which will be implemented to power MOSFET. Equation (18) can be rewritten in a simpler way as:

$$
d=1-\frac{u}{i_{L Y}}
$$

Figure 5 illustrates the closed-loop form of the PI controller based on Equation (18). Since the goal is receiving a fixed DC voltage at the endpoints of the converter on the load side, a sampling of this voltage was done and compared with a reference voltage in order to be applicable by a microcontroller. Therefore, the sampled voltage should be at a comparable level of the reference voltage. For example, for a $120 \mathrm{~V}$ as the fixed output voltage, if the reference voltage chosen is $4 \mathrm{~V}$, the sampled voltage should be decreased through high resistors and be equal to $4 \mathrm{~V}$. For other amounts of the output voltage above or under the $120 \mathrm{~V}$, this sampled voltage will change between 3 to $5 \mathrm{~V}$ to be comparable with the reference voltage. After passing through the controller, the control signal u will be compared with the current of the second inductor $i_{L Y}$, and as Equation (19) shows, the desired duty cycle is supplied for the power switch. Figure 6 presents the controller structure for the proposed converter.

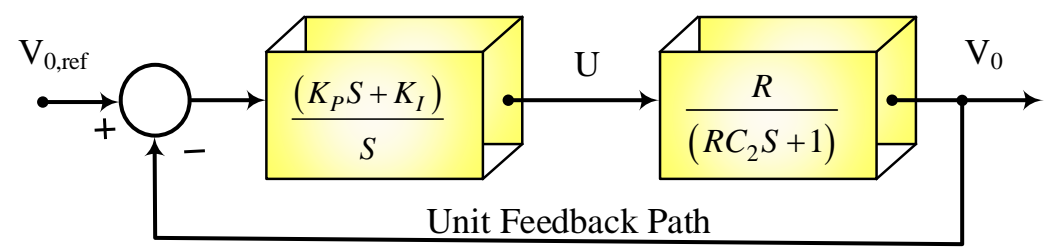

Figure 5. Closed-loop form of the Proportional-Integral (PI) controlled cascade boost structure. 


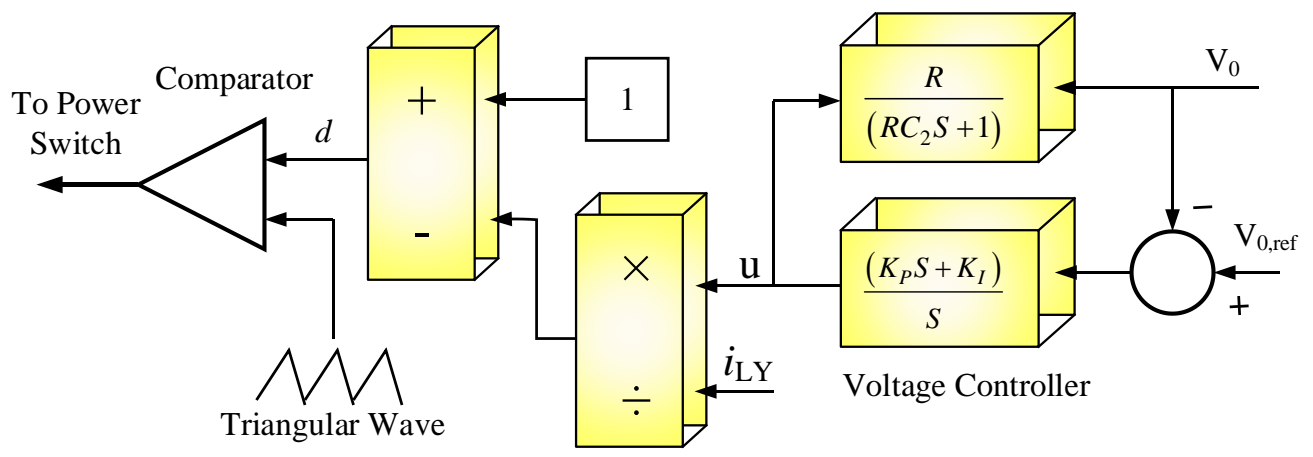

Figure 6. Voltage comparison, PI control, and PWM modulator blocks.

The general form of a PI controller comes from:

$$
G(s)=k_{p}+\frac{k_{i}}{s}=\frac{k_{p} s+k_{i}}{s} \quad \text { or } \quad G(j \omega)=k_{p}+\frac{k_{i}}{j \omega}
$$

where $K_{P}$ and $K_{I}$ are the proportional and integral gains of the PI controller. We can put Equation (20) in a feedback loop by a PI controller as presented in Figures 5 and 6 by considering Equation (19). The transfer function of closed-loop form of this feedback is equal with:

$$
G_{F}=\frac{G_{o}}{1+G_{0}}=\frac{\frac{1}{C_{2}}\left(k_{p}+k_{i}\right)}{s^{2}+\left(\frac{1+R k_{p}}{R C_{2}}\right)+\frac{k_{i}}{C_{2}}} \Rightarrow G_{F}=\frac{\frac{1}{C_{2}}\left(k_{p} s+k_{i}\right)}{s^{2}+2 \xi \omega_{0} s+\omega_{o}^{2}}
$$

$K_{P}$ and $K_{I}$ are the proportional and integral coefficients of the PI controller. It is easy to gain:

$$
\left\{\begin{array} { r l } 
{ \frac { 1 + R k _ { p } } { R C _ { 2 } } } & { = 2 \xi \omega _ { 0 } } \\
{ \frac { k _ { i } } { C _ { 2 } } } & { = \omega _ { 0 } ^ { 2 } }
\end{array} \Rightarrow \left\{\begin{array}{c}
k_{p}=2 \xi \omega_{0} C_{2}-\frac{1}{R} \\
k_{i}=\omega_{0}^{2} C_{2}
\end{array}\right.\right.
$$

The representation of the frequency domain in the $\mathrm{kp}$ and ki plane can be introduced by:

$$
\left[\begin{array}{cc}
X_{R p} & X_{R i} \\
X_{I p} & X_{I i}
\end{array}\right]=\left[\begin{array}{c}
k_{p} \\
k_{i}
\end{array}\right]=\left[\begin{array}{c}
0 \\
-\omega_{0}
\end{array}\right]
$$

By solving this equation for $\omega \neq 0$;

$$
\begin{gathered}
K_{p}\left(\omega, \theta_{A}, \xi\right)=\frac{-\operatorname{Re}(\omega)-\frac{1}{\xi}\left(A_{A} \cos \theta_{A}-B_{A} \sin \theta_{A}\right)}{X(\omega)} \\
K_{I}\left(\omega, \theta_{A}, \xi\right)=\frac{\omega\left(\operatorname{Im}(\omega)+\frac{1}{\xi}\left(A_{A} \sin \theta_{A}+B_{A} \cos \theta_{A}\right)\right)}{X(\omega)} \\
X(\omega)=\left(\begin{array}{c}
\left|G_{p}(j \omega)\right|^{2}+\frac{1}{\xi^{2}}\left|W_{A}(j \omega)\right|^{2}+\frac{2}{\xi}\left(\operatorname{Re}(\omega)\left(A_{A} \cos \theta_{A}-B_{A} \sin \theta_{A}\right)\right. \\
\left.+\operatorname{Im}(\omega)\left(A_{A} \sin \theta_{A}+B_{A} \cos \theta_{A}\right)\right)
\end{array}\right)
\end{gathered}
$$

For $\omega 0=0$, Equation (24) will result in:

$$
\left[\begin{array}{cc}
0 & X_{R i}(0) \\
0 & X_{I i}(0)
\end{array}\right]=\left[\begin{array}{l}
k_{p} \\
k_{i}
\end{array}\right]=\left[\begin{array}{l}
0 \\
0
\end{array}\right]
$$

For this equation, it can be found that $K_{P}$ is an arbitrary factor while $K_{I}(0, \theta A, \xi)=0$, unless $X_{R i(0)}$ $=X_{I i(0)}=0$, which can be possible only under $\xi \rightarrow \infty$ and $\operatorname{Rp}(0)=\operatorname{Ip}(0)=0$ conditions, which holds by a zero for $\mathrm{Gp}(\mathrm{S})$ at the origin. Therefore, damping factor $\xi$ was selected as 0.707 , which can present a 
good response for the second order circuits [21]. Since $\omega_{0}$ is a pulsation, it was chosen as less than the switching frequency $\omega s$ to get an appropriate response. Based on [21], this factor can be introduced as Equation (28):

$$
\frac{f_{P W M}}{5 \xi} \leq \omega n \leq \frac{f_{P W M}}{2 \xi}
$$

By decreasing the $\omega_{\mathrm{n}}$ value, the bandwidth of the control system will reduce and will give the increased dither amplitude attenuation and longer set-up times, enhancing the $\omega_{\mathrm{n}}$ value above the presented band, and resulting in the poor matching of the linearized model's response to the actual system. This is due to the effect of sampling on the frequency response of the system. In our calculations, the pulsation frequency was fixed to $230.63 \mathrm{rad} / \mathrm{s}$ with the consideration of the calculated $K_{p}$ and $K_{I}$ values based on Equation (22), and the switching frequency was adjusted to $50 \mathrm{kHz}$, so $\omega_{\mathrm{S}}=2 \pi \mathrm{f}_{\mathrm{S}}$ is equal to $314 \mathrm{~K} \mathrm{rad} / \mathrm{s}$.

\subsection{Comparison of the Conventional Cascaded and Proposed Converters}

The main purpose of this section was a comparison between the inductor currents and capacitor voltage ripples for a classical cascade and our proposed converters. Table 1 summarizes these equations. In this table, $V_{C 1}$ and $V_{C 0}$ are the steady state voltages of the $C_{1}$ and $C_{2}$ capacitors; $D_{1}$ and $D_{2}$ are the duty cycles of PWM signals for $S_{1}$ and $S_{2}$ power MOSFETs of the conventional cascaded boost converter; $D$ is the duty cycle for the proposed converter's switch, respectively; $T_{S}$ is the switching frequency; and $\Delta i_{L X}$ and $\Delta i_{L Y}$ are the current ripples for the inductors $L_{X}$ and $L_{Y}$, respectively. Additionally, $I_{0}$ is the output current and $V_{i n}$ is the input voltage of the structures.

Table 1. Capacitor voltage and inductor current ripples for both converters.

\begin{tabular}{cc}
\hline \multicolumn{2}{c}{ Classical Cascaded Converter } \\
\hline First Block & Second Block \\
\hline$\Delta i_{L X}=\frac{V_{\text {in }}}{L_{X}} D_{1} T_{s}$ & $\Delta i_{L Y}=\frac{V_{C 0}-V_{C 1}}{L_{Y}}\left(1-D_{2}\right) T_{s}$ \\
$\Delta V_{C 1}=\frac{I_{L Y}}{C_{1}} D_{1} T_{s}$ & $\Delta V_{C 0}=I_{o} D_{2} T_{s}$ \\
\hline \multicolumn{1}{c}{ Proposed Converter } \\
\hline$\Delta i_{L X}=\frac{V_{\text {in }}}{L_{X}} D T_{s}$ & $\Delta i_{L Y}=\frac{\left(V_{C 0}-V_{C 1}\right)-V_{i n}}{L_{Y}}(1-D) T_{s}$ \\
$\Delta V_{C 1}=\frac{I_{L X}}{C_{1}} D T_{s}$ & $\Delta V_{C 0}=I_{o} D T_{s}$ \\
\hline
\end{tabular}

By considering the same duty cycle for all switches, the current ripples for inductors were the same for both configurations, while the proposed converter uses only one power switch and has a simpler structure and needs to simple with a one controller topology to guarantee a fixed output voltage at the output of the converter. Part of simulations is presented in Section 3, and can show the first inductor currents, output diode currents, power switch currents, and the average values of these converters. All results can easily confirm the equations presented in Table 1.

Table 2 illustrates all of the component conduction and switching losses for both conventional, cascaded, and proposed power boost converters comprehensively. This table was written according to [22]. In this table, the $P_{c o n}$ and $P_{s w}$ are the conductive and switching losses, respectively. For example, $P_{c o n, D 1}$ is the conductive losses of the power diode $D_{1}$ and $P_{s w, D 2}$ is the switching losses for the diode $D_{2} . P_{L X}$ and $P_{L Y}$ are the conductive losses on inductors. Additionally, $V_{f}$ is the forward voltage on diodes; $f_{S}$ is the frequency switching value; and $Q_{r r 1}, Q_{r r 2}$, and $Q_{r r 3}$ are the electrical charges of the $D_{1}$, $D_{2}$, and $D_{0}$ diode forward capacitors. $T_{O N}$ and $T_{O F F}$ are presenting the transition times for the power switches for the ON and OFF states, respectively. The dissipated energy for the turn ON and OFF 
momentary times are presented by $W_{O N}$ and $W_{O F F}$. $D^{\prime}$ presents the time that the power switch is in OFF mode.

Table 2. Equations for both converters operating in continuous conduction mode (CCM).

\begin{tabular}{|c|c|}
\hline Conventional Cascade Converter & Proposed Converter \\
\hline$I_{L X}=\frac{1}{\left(1-d_{1}\right) \times\left(1-d_{2}\right)} \times \frac{V_{0}}{R}$ & $I_{L X}=\frac{1}{(1-d)^{2}} \times \frac{V_{o}}{R}$ \\
\hline$I_{L X}=\frac{1}{\left(1-d_{2}\right)} \times \frac{V_{0}}{R}$ & $I_{L 2}=\frac{1}{(1-d)} * \frac{V_{o}}{R}$ \\
\hline$P_{L X}=R_{L X}\left(i_{L X}^{2}+\frac{\Delta i_{L X}^{2}}{12}\right)$ & $P_{L X}=R_{L X}\left(i_{L X}^{2}+\frac{\Delta i_{L X}^{2}}{12}\right)$ \\
\hline$P_{L Y}=R_{L Y}\left(i_{L Y}^{2}+\frac{\Delta i_{L Y}^{2}}{12}\right)$ & $P_{L Y}=R_{L Y}\left(i_{L Y}^{2}+\frac{\Delta i_{L Y}^{2}}{12}\right)$ \\
\hline$P_{c o n D 1}=V_{f 1} I_{L X} D_{1}^{\prime}+R_{o n D 1} D_{1}^{\prime}\left(I_{L X}^{2}+\frac{\Delta i_{L X}^{2}}{12}\right)$ & $\begin{array}{c}P_{c o n D 1}= \\
V_{f 1}\left(I_{L X}+I_{L Y}\right) D_{1}^{\prime}+R_{o n D 1} D_{1}^{\prime}\left(\left(I_{L X}+I_{L Y}\right)^{2}+\frac{\Delta i_{L X}^{2}}{12}\right)\end{array}$ \\
\hline$P_{c o n D 2}=V_{f 2} I_{L 2} D_{2}^{\prime}+R_{o n D 2} D_{2}^{\prime}\left(I_{L 2}^{2}+\frac{\Delta i_{L 2}^{2}}{12}\right)$ & $\begin{array}{c}P_{\text {conD2 } 2}= \\
V_{f 2}\left(I_{L 1}+I_{L 2}\right) D_{2}^{\prime}+R_{o n D 2} D_{2}^{\prime}\left(\left(I_{L 1}+I_{L 2}\right)^{2}+\frac{\Delta i_{L 1}^{2}}{12}\right)\end{array}$ \\
\hline$P_{\text {conD0 }}=0$ & $\begin{array}{c}P_{\text {conD0 } 0}= \\
V_{f 3}\left(I_{L X}+I_{L Y}\right) D_{2}^{\prime}+R_{o n D 3} D_{2}^{\prime}\left(\left(I_{L X}+I_{L Y}\right)^{2}+\frac{\Delta i_{L X}^{2}}{12}\right)\end{array}$ \\
\hline$P_{c o n M 1}=R_{d s M 1} D_{1}\left(I_{L X}^{2}+\frac{\Delta i_{L X}^{2}}{12}\right)$ & $P_{c o n M}=R_{d s M} D\left(I_{L X}^{2}+\frac{\Delta i_{L X}^{2}}{12}\right)$ \\
\hline$P_{c o n M 2}=R_{d s M 2} D_{1}\left(I_{L Y}^{2}+\frac{\Delta i_{L Y}^{2}}{12}\right)$ & $P_{\text {conM2 }}=0$ \\
\hline$P_{s w D 1}=V_{c 1} Q_{r r 1} f_{s}$ & $P_{s w D 1}=V_{c 1} Q_{r r 1} f_{s}$ \\
\hline$P_{s w D 2}=V_{c 2} Q_{r r 2} f_{s}$ & $P_{s w D 2}=V_{c 2} Q_{r r 2} f_{s}$ \\
\hline$P_{s w D 0}=0$ & $P_{s w D 0}=V_{c 3} Q_{r r 3} f_{s}$ \\
\hline $\begin{array}{c}P_{\text {SwM1 } 1}=\left(W_{\text {ON1 }}+W_{\text {OFF } 1}\right) f_{s} \\
W_{O N 1}=0.5 I_{L X} V_{C 1} T_{\text {on } 1} \\
W_{O F F 1}=0.5 I_{L X} V_{C 1} T_{\text {OFF } 1}\end{array}$ & $\begin{array}{c}P_{\text {SwM1 }}=\left(W_{\text {ON1 }}+W_{O F F 1}\right) f_{s} \\
W_{O N 1}=0.5 I_{L X} V_{C 1} T_{O N 1} \\
W_{O F F 1}=0.5 I_{L X} V_{C 1} T_{O F F 1}\end{array}$ \\
\hline $\begin{array}{c}P_{\text {SwM2 }}=\left(W_{\text {ON2 }}+W_{\text {OFF2 }}\right) f_{S} \\
W_{\text {ON2 }}=0.5 I_{L Y} V_{C 2} T_{\text {ON2 }} \\
W_{O F F 2}=0.5 I_{L Y} V_{C 2} T_{\text {OFF2 }}\end{array}$ & $P_{s w M 2}=0$ \\
\hline
\end{tabular}

The main advantage of the proposed converter is that it has only one power switch. Therefore, there are no conductive and switching losses for the second power switch. In addition, it should be considered that it has three power diodes compared with a conventional cascaded converter and the projected converter will have these losses for the third diode. This presents a preferable condition compared with conventional cascaded structures.

\subsection{Comparison of the Conventional Cascaded and Proposed Converters}

By considering the ideal conditions for all inductors, capacitors, power diodes, and power switches, the voltage gain of the proposed converter can be obtained. Based on the charging and discharging states of inductors, mathematical evaluation for the voltage gain will appear in two different modes.

State 1: Voltage across inductor $L_{X}$ when the power switch is in ON and OFF modes:

The voltage across inductor $L_{X}$ will be equal with:

$$
V_{\text {in }} D+\left(V_{\text {in }}-V_{C 1}\right)(1-D)=0 \Rightarrow V_{C 1}=\frac{V_{\text {in }}}{1-D}
$$

In the above equation, $\mathrm{D}$ is for a time interval where the switch is in $\mathrm{ON}$ mode and (1-D) is for the OFF state of MOSFET. 
State 2: Voltage across inductor $L_{Y}$ when the power switch is in ON and OFF modes:

The voltage drops can be calculated as Equation (29):

$$
V_{C 1} D+\left(V_{C 1}-V_{0}\right)(1-D)=0 \Rightarrow V_{0}=\frac{V_{C 1}}{1-D}
$$

By replacing Equation (28) into Equation (29), the voltage gain of the proposed structure can be calculated:

$$
V_{0}=\frac{V_{\text {in }}}{(1-D)^{2}}
$$

Therefore, the voltage gain of the proposed structure can be obtained by Equation (32):

$$
G=\frac{V_{0}}{V_{\text {in }}}=\frac{1}{(1-D)^{2}}
$$

Through a simple calculation, the relation between the input and output current values can be calculated as:

$$
I_{0}=I_{i n}(1-D)^{2}
$$

For the proposed converter, we can find the values of the inductor currents from the below equations:

$$
\left.\begin{array}{rl}
\Delta i_{L X} & =\frac{V_{\text {in }}}{L_{x}} d T \\
I_{L X} & =\frac{I_{0}}{(1-d)^{2}}
\end{array}\right\}
$$

So, the oscillation of the current for these inductors can be presented by:

$$
\begin{aligned}
& \xi_{1}=\frac{\Delta i_{L X} / 2}{I_{L X}}=\frac{d(1-d)^{2} T V_{i n}}{2 L_{X} I_{O}}=\frac{d(1-d)^{4}}{2} \frac{R}{f L_{X}} \\
& \xi_{2}=\frac{\Delta i_{L Y} / 2}{I_{L Y}}=\frac{d(1-d) T V_{C 1}}{2 L_{Y} I_{O}}=\frac{d(1-d)^{2}}{2} \frac{R}{f L_{Y}}
\end{aligned}
$$

Additionally, the voltage fluctuation for the output capacitor can be presented by Equation (37):

$$
\varepsilon=\frac{\Delta V_{0} / 2}{V_{0}}=\frac{1-d}{2 R f C_{0}}
$$

For the simulation and experimental analysis, considered one percent for these oscillations, the values of the inductors and capacitors can be calculated.

\section{Simulation Results and Discussion}

A group of simulations were performed in MATLAB SIMULINK R2017a for the evaluation and testing of the stability of the proposed circuit. The input voltage for the structure was adjusted between 25 and $45 \mathrm{~V}$ based on the panel's ability to generate voltage according to different temperature and irradiance values. The output load value was chosen between 50 and $200 \mathrm{ohms}$ for an output power limit of around $288 \mathrm{~W}$. Additionally, $50 \mathrm{kHz}$ was considered as the switching frequency. Simulations were done for the duty cycle from $30 \%$ to $90 \%$ and the results are presented in this section. Table 3 presents all of the components and parameters that were used in the simulation.

For our tests, we assumed $0.1 \Omega$ for inductors $L_{X}$ and $L_{Y}$ as their internal resistance. This value of the internal resistance was tested on a real $200 \mu \mathrm{H}$ inductor in the laboratory. For that, a fixed $0.5 \mathrm{~V}$ 
implemented on the inductor and serial ammeter showed around $5 \mathrm{~A}$ as the current. Figure $7 \mathrm{a}$ presents the I-V and P-V characteristics of the JIYANGYIN HR-200 W type of the PV array that was selected for hardware implementation. The level of the input voltage and power array were in a good domain of the desired issues presented in Table 3. Figure $7 \mathrm{~b}$ illustrates the final diagram of the proposed converter and controller and as can be seen, a sampling was done based on Equation (9) for the controller design. This diagram is suitable for all kinds of renewable energy sources since these produce limited values of power. The controller loop was drawn based on Equations (18) and (19) and Figures 5 and 6. For the controller, PIC18f877 was selected to do the comparison between the reference and sampled voltages and a triangular wave with a $50 \mathrm{kHz}$ frequency was implemented for duty cycle generation to drive the power switch.

Table 3. Particularization of the projected and conventional boost converters in the simulation and experimental steps.

\begin{tabular}{ccc}
\hline Parameter & Proposed Structure & Conventional Cascade Structure \\
\hline Power & $288 \mathrm{~W}$ & $288 \mathrm{~W}$ \\
Input voltage & $20-45 \mathrm{~V}$ & $20-45 \mathrm{~V}$ \\
$L_{X}$ and $L_{Y}$ & $200 \mathrm{uH}$ & $200 \mathrm{uH}$ \\
ESR of inductors & $0.1 \Omega$ & $0.1 \Omega$ \\
$C_{1}$ & $1 \mathrm{uF}$ & $47 \mathrm{uF}$ \\
$C_{0}$ & $47 \mathrm{uF}$ & $47 \mathrm{uF}$ \\
Duty cycle & $30-90 \%$ & $30-90 \%$ \\
Switching frequency & $50 \mathrm{kHz}$ & $50 \mathrm{kHz}$ \\
\hline
\end{tabular}

Figure 8 shows the efficiency diagram and was done with a comparison between the conventional cascaded and projected prototypes. The most important reason for the comparable efficiency value for the new converter is its components, especially the power diodes. As mentioned in Section 2.1, in any time interval of PWM, only one diode will be located in the current direction and will charge the inductors or output capacitor. Additionally, this structure has only one power switch and the same inductor and capacitor values when compared with conventional topologies. As expected, both the proposed and cascaded converters can present low efficiency for lower power based on some fixed losses on devices, and for higher values of power, both structures will be more efficient. By considering that in any time interval two diodes will be active for both topologies by the same number of inductors and since the average current of the proposed converter is approximately equal with the total currents of both MOSFETs of the cascaded converter, efficiency values were obtained close to each other. This figure has been presented for a fixed load with a $200 \Omega$ value and different values of input voltages.

A low-pass filter can be a single-tuned or doubled-tuned filter. This is a technique of eliminating a particular current harmonic by tuning a low-pass filter to a specific frequency that uses low impedance such as 5th multiple or 7th multiple harmonics of the fundamental. High-pass filters on the other hand also consist of passive components with less impedance for harmonics at specific frequencies, thus filtering all harmonics present with higher frequencies [22]. These filters can be configured as the first order, second order, third order, and fourth-order high pass filters. The first order filters are the simplest form of high-pass filters, containing only one passive component. The order of the high-pass determines the number of component(s) contained in the filter and the higher-order provides better stability to the power system. In our study, we simply applied a capacitor between the PV panel and boost converter. Additionally, the MPPT algorithm of the boost converter helps to decrease the current harmonics of the topology and increase the efficiency. 

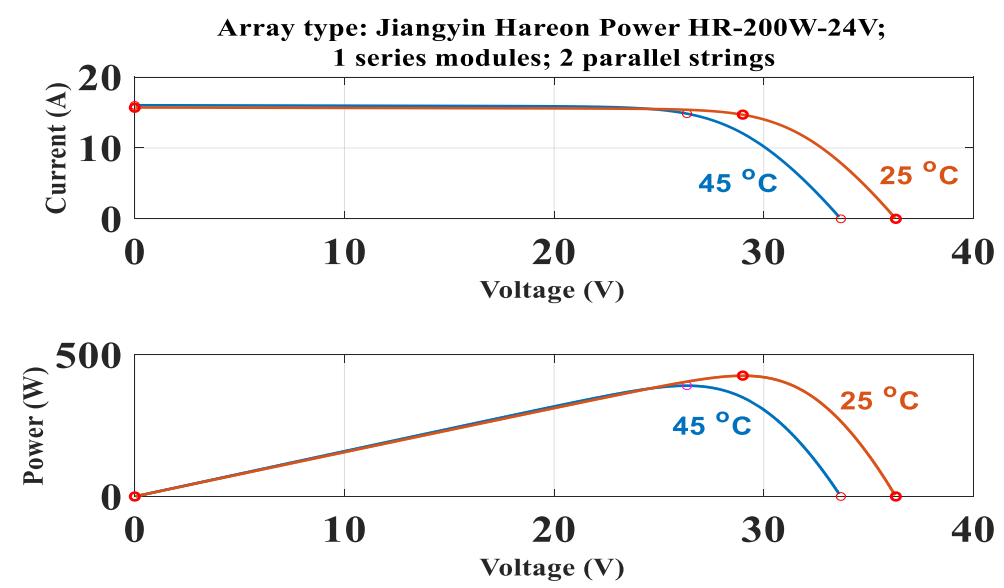

(a)

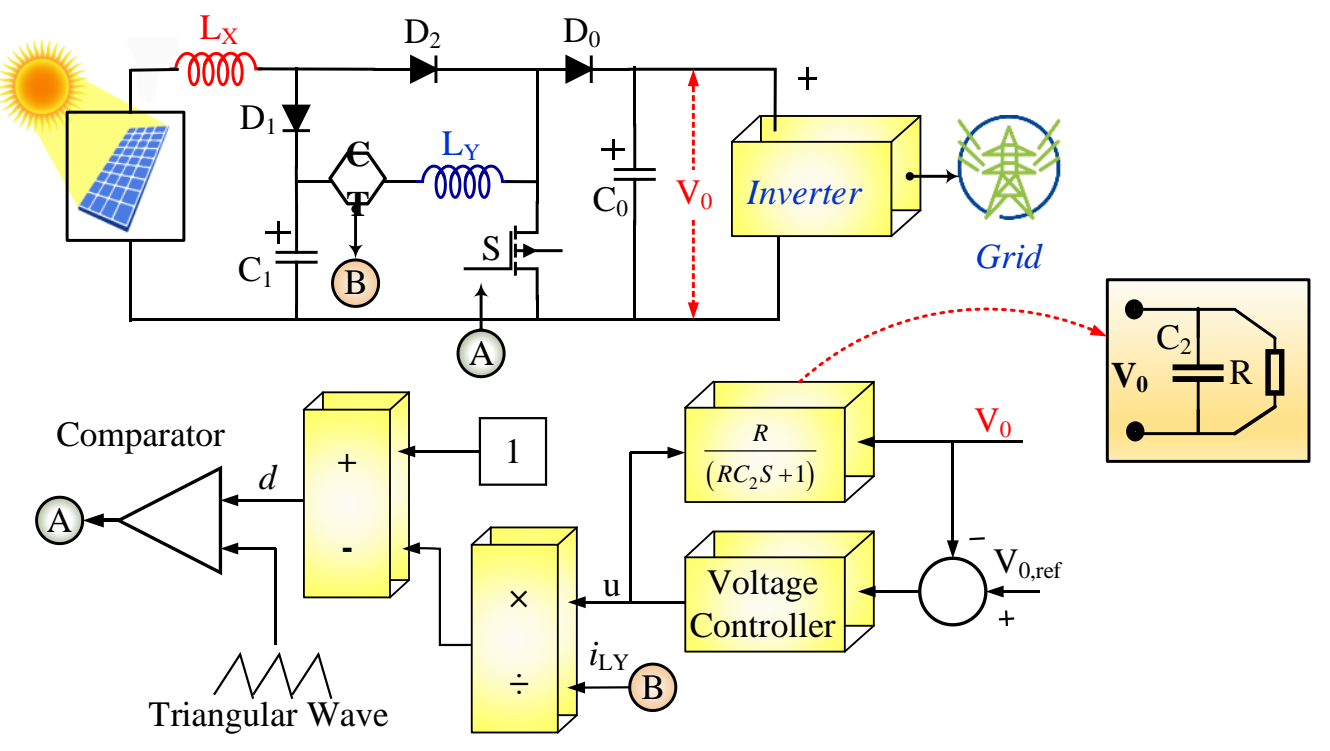

(b)

Figure 7. (a) Current-Voltage (I-V) and Power-Voltage (P-V) characteristics of the applied PV arrays and $(\mathbf{b})$ the proposed structure with the designed controller block.

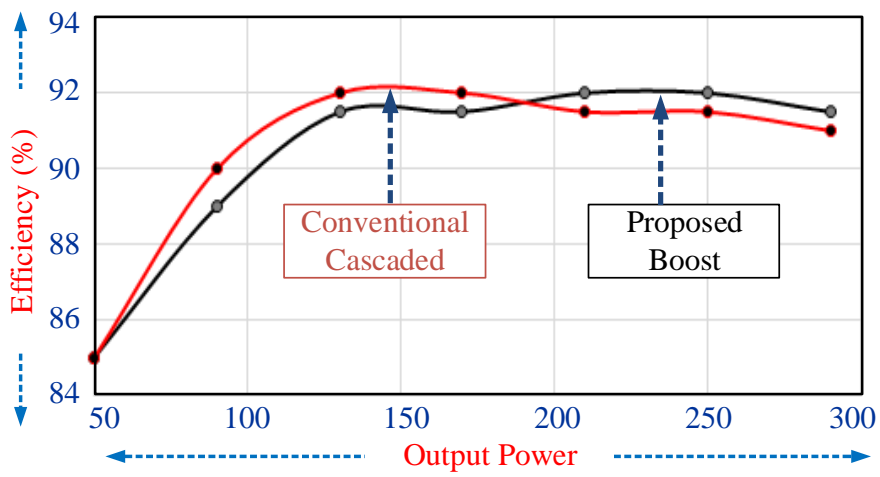

Figure 8. Efficiency diagram for the proposed and conventional cascaded structures.

Figure 9a shows the voltage gain for the proposed and conventional boost circuits in $50 \%$ of the duty cycle and 50 to $200 \Omega$ as the load. One of the most important issues for a boost converter is the converter's ability to gain production since voltage transfer is preferred, rather than the current transition in all parts of fossil or renewable energy sources. 
The simulation was conducted from $50 \mathrm{~W}$ to around $290 \mathrm{~W}$ of the output power and for all of this band, the proposed converter presented higher DC gain. Additionally, Figure $9 \mathrm{~b}$ illustrates a comparison diagram between the classical cascade and proposed topologies voltage gain for this band of output power for different values of duty cycles from 30 to $90 \%$. The same result is reported for this test.

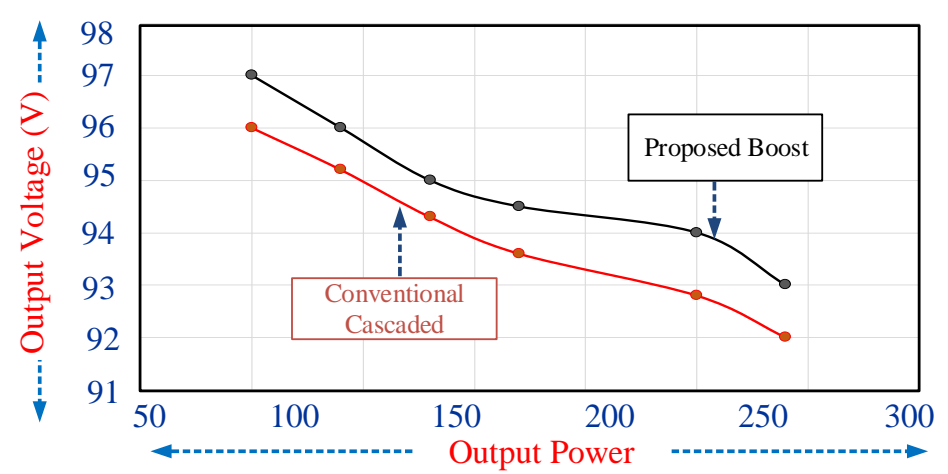

(a)

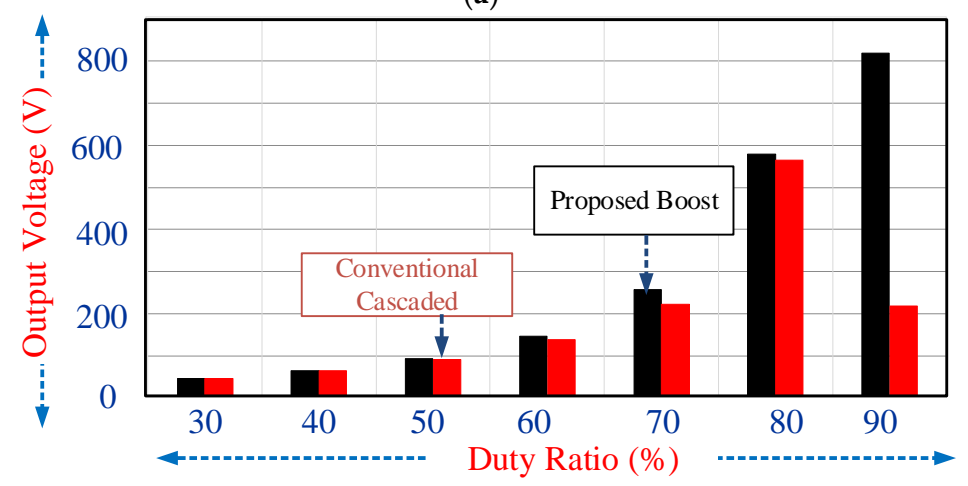

(b)

Figure 9. (a) Voltage gain diagram for the proposed and conventional cascaded structures in real and ideal states based on different (a) loads and (b) duty cycles.

Figure 10 illustrates the controller performance and stability in producing different voltages in output. For this simulation, the input supply was fixed to $24 \mathrm{~V}$ and the reference voltage was changed between $80 \mathrm{~V}, 100 \mathrm{~V}$, and $120 \mathrm{~V}$. For our tests, in order to carry out the PWM implementation to gate-source pins of the power semiconductor switch, the triangle waveform was considered with a $50 \mathrm{kHz}$ frequency. By considering the damping factor for the proposed controller at the change points of the output voltage, a limited value of the overshoot was reported. These overshoot values can have smaller values with PI controller internal adjustments in MATLAB/SIMULINK for the upper and lower output limits, which is applicable for an embedded controller like the M9036A and M9037A or MEC1609 series. 


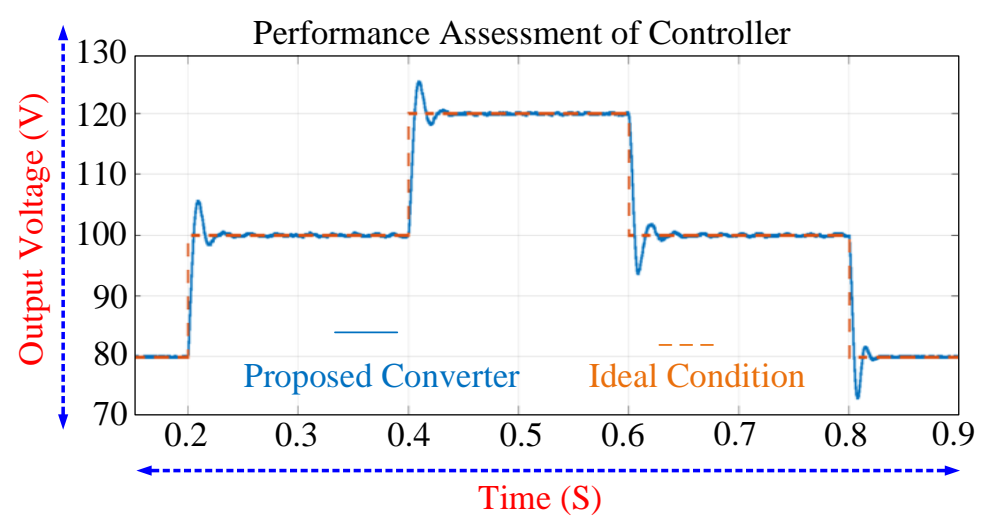

Figure 10. Tracking and ability to obtain different output voltages by the proposed controller.

Figure 11 presents the performance of the controller to present the fixed voltage at the load side by changing the input voltage values. As known, PV panels based on different irradiance and temperatures present different values of voltages. Therefore, one of the specifications of a good converter and controller is the ability in obtaining a fixed DC voltage for load by different values of the input voltage. Therefore, in the worst condition, if both the input voltage and output load change, we should consider the performance of the controller for reliability analysis. Figure 11 presents the reaction of the controller for input voltages from $25 \mathrm{~V}$ to $45 \mathrm{~V}$ and load values from $50 \Omega$ to $200 \Omega$. As reported in Figure 11a, and as expected, for higher loads where higher currents are needed, the overshoot is higher and the settling time is longer. For a higher amount of input voltages and lower amount of output currents, as Figure 11c presents, both overshoot value and settling time are less. In addition, it can be found that when the input voltage is higher for a fixed load, the overshoot is less and settling time is shorter.

Figure 12 illustrates the current values for the power MOSFETs, output diodes, and input inductors of around $50 \mathrm{~W}$ of output power. As can be seen from Figure 12a,b, approximately the average value of the current for the switch in the proposed converter was equal with the total currents of switches in the cascaded converter. In fact, we should make a trade-off between having two different power MOSFETs with two controller structures and only one power MOSFET with only one controller. Moreover, for the new $\mathrm{SiC}$ generation of power MOSFETs, we can present a quick and stable converter and resonant snubber structures can be used to decrease these stresses. Figure $12 \mathrm{c}, \mathrm{d}$ show that the proposed converter can present a lower amount of currents for the input inductor and output diode. However, this difference was not impressive. In general, as the mathematical analysis shows, the total losses of the proposed converter are comparable with the cascaded converter and for higher amount of power, it is more efficient.

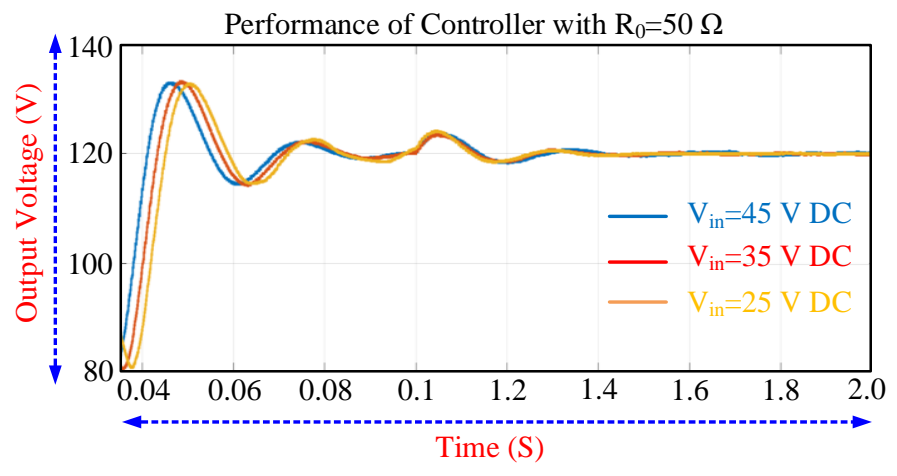

(a)

Figure 11. Cont. 


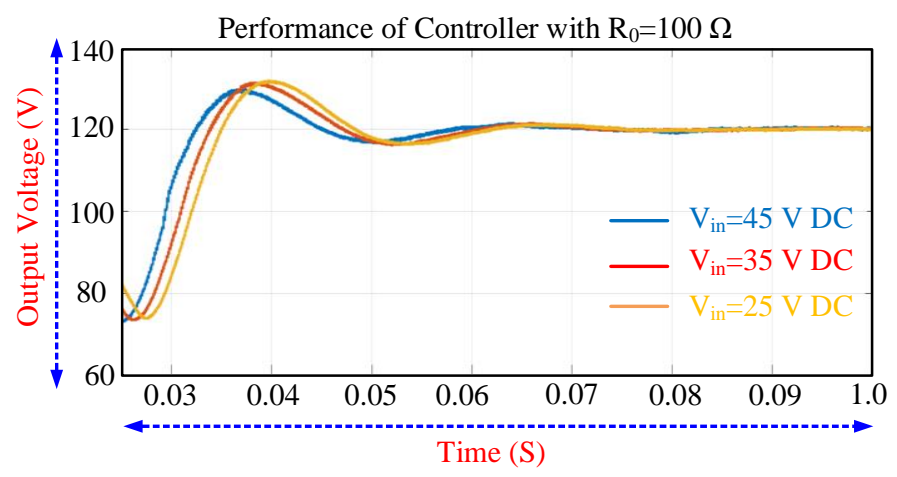

(b)

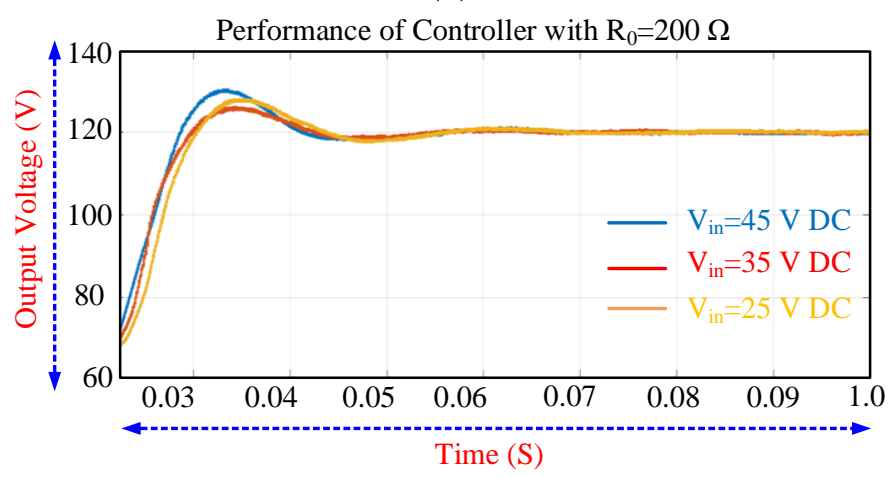

(c)

Figure 11. Tracking of the desired voltage in the proposed converter when the input voltage changes from $25 \mathrm{~V}$ to $45 \mathrm{~V}$ and the loads are (a) $50 \Omega$; (b) $100 \Omega$, and (c) $200 \Omega$.

Figure 13 illustrates the current wave form for the input side of the boost converter. As can be seen, the performance of the capacitor as the simple input passive filter was considerable and under the control procedure by the proposed PI controller, a very high quality current wave form could be obtained. This current guarantees a pure DC current for the load.

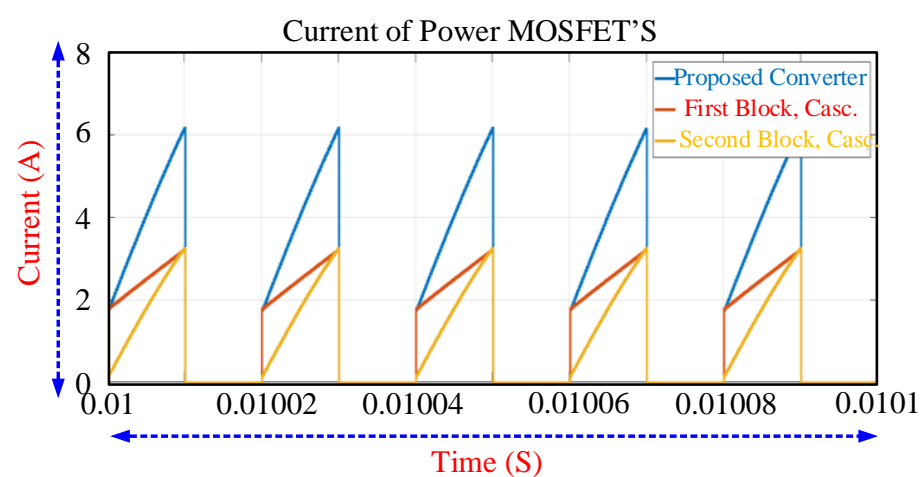

(a)

Figure 12. Cont. 


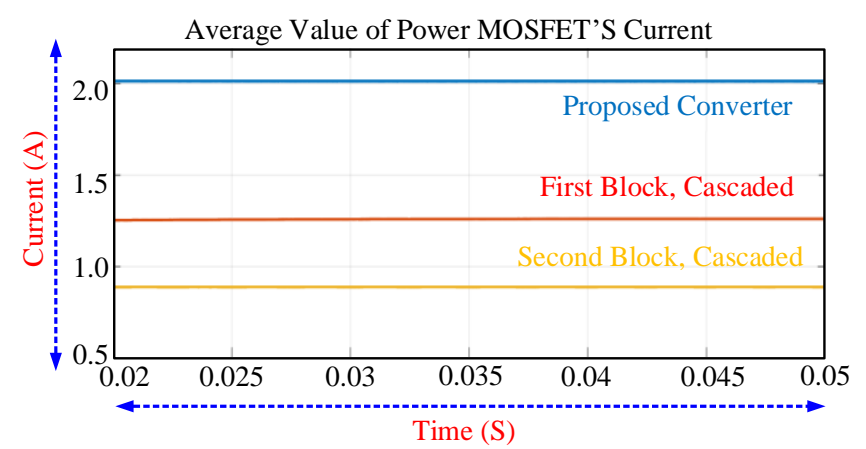

(b)

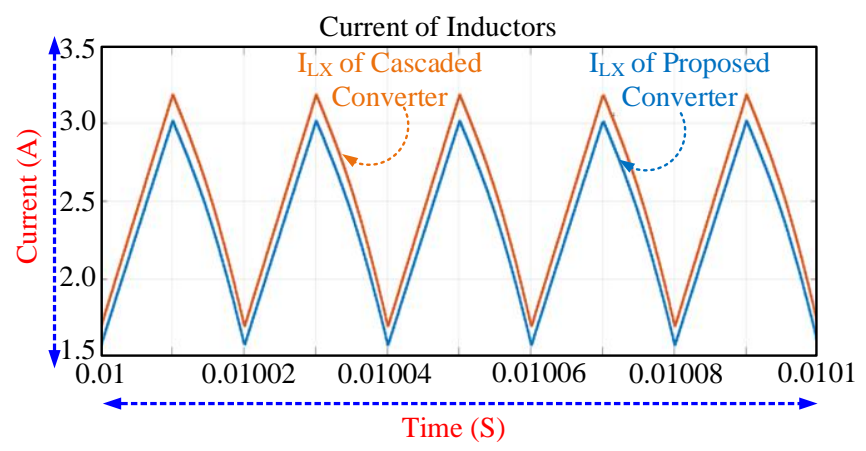

(c)

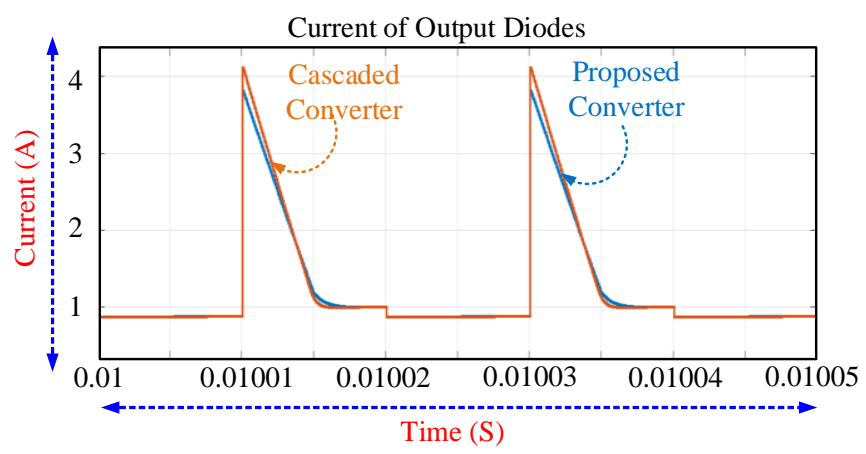

(d)

Figure 12. (a) Current wave forms for the power MOSFETs and (b) average of these currents; currents for the (c) input inductors, and (d) output diode.

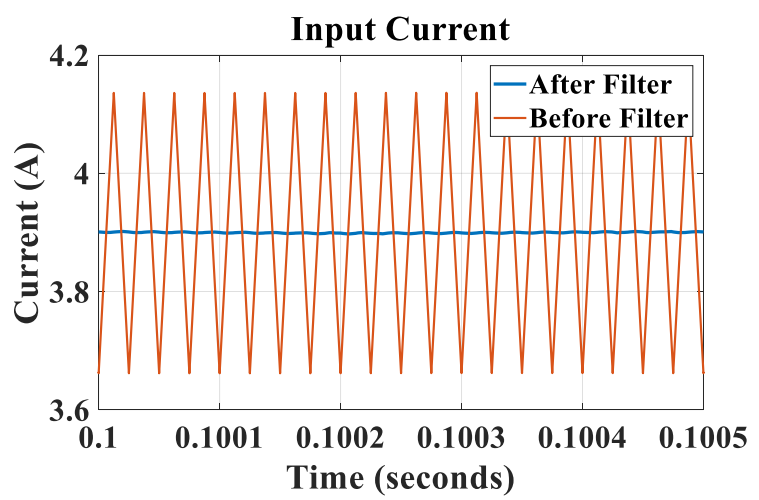

Figure 13. The reaction of the input current under performance of the passive filter and proposed controller. 


\section{Experimental Results and Discussion}

A prototype with around $100 \mathrm{~W}$ was implemented and Figures 14-17 show the results. The switching frequency was set to $50 \mathrm{kHz}$. Inductors $L_{X}$ and $L_{Y}$ were fixed to $200 \mathrm{uH}$, the capacitor $C_{1}$ value was considered as $1 \mu \mathrm{F}$, and the output capacitor $\mathrm{C} 2$ as $47 \mathrm{uF}$. Figure 14 presents the hardware prototype. Figure 15 shows the gate source and drain source pulses of the structure in $50 \%$ and $75 \%$ of duty cycles and as we expected, different values of ON and OFF intervals of power MOSFET and as a result, different duty cycles for the voltages of drain-source pins were obtained. Figure 16 illustrates the voltage waveforms for the capacitors and currents of the inductors.

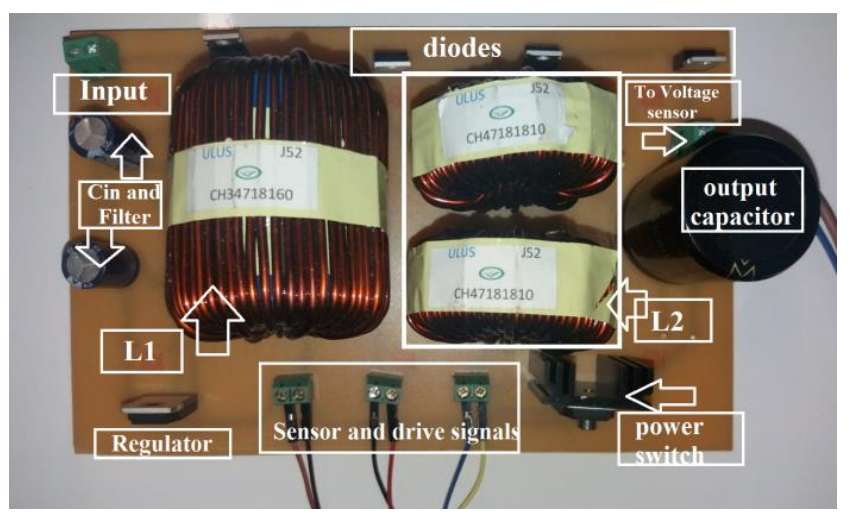

Figure 14. Hardware prototype.

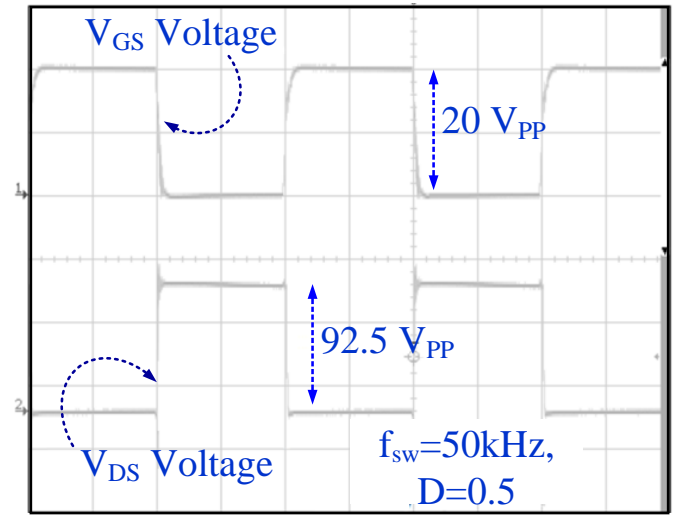

(a)

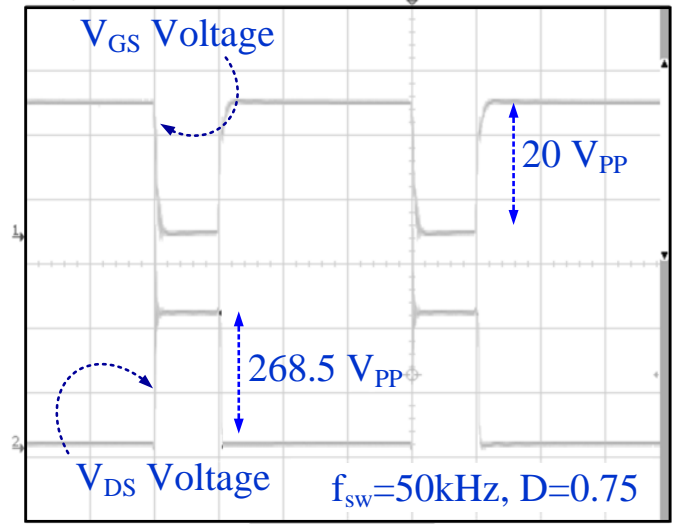

(b)

Figure 15. Gate source and drain-source voltages of the projected structure when the duty cycle is (a) $50 \%$ and (b) $75 \%$.

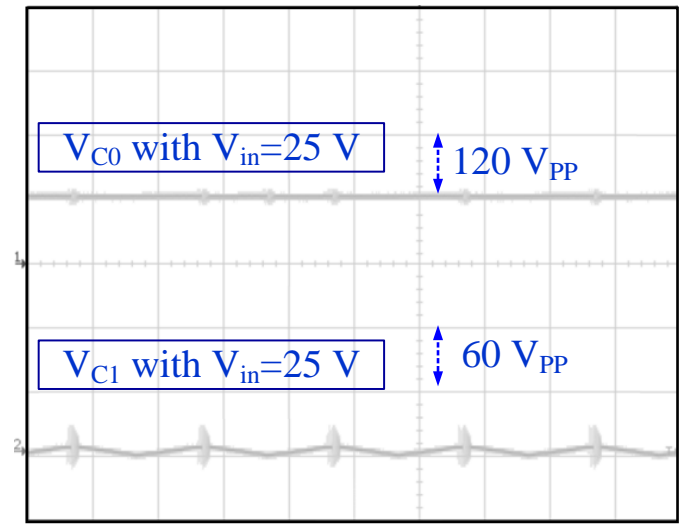

(a)

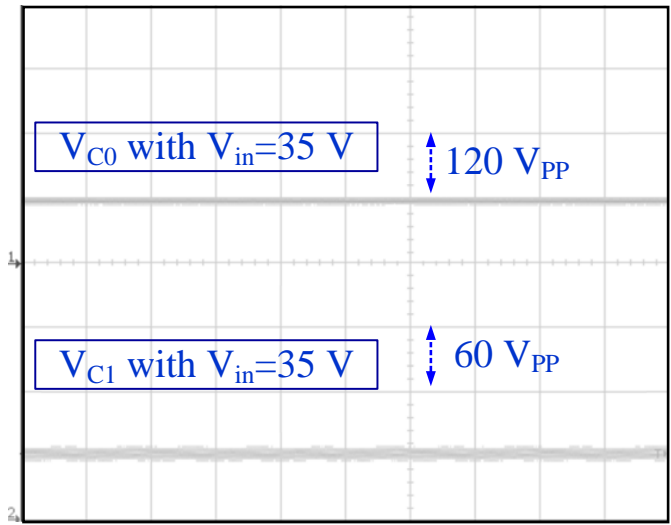

(b)

Figure 16. Cont. 


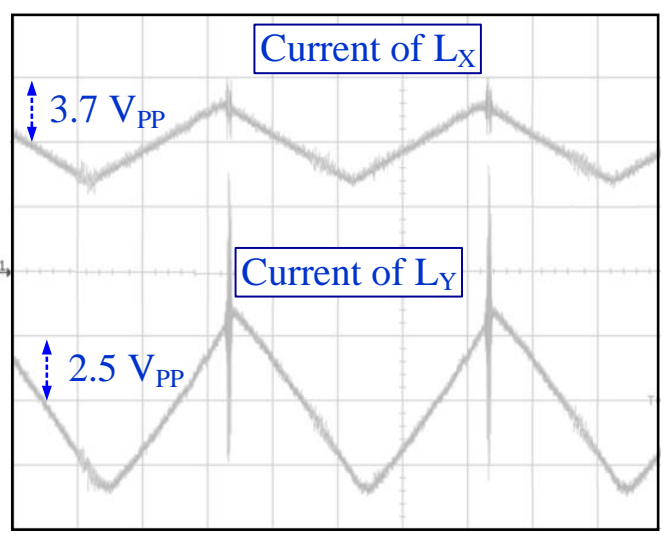

(c)

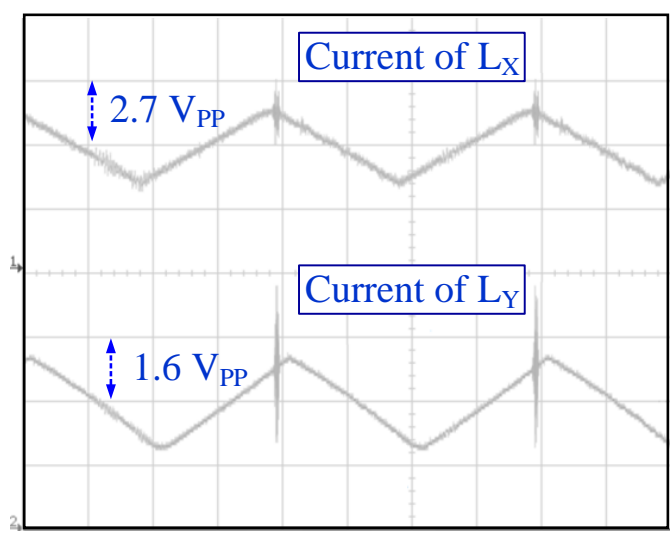

(d)

Figure 16. Voltage through capacitors $C_{1}$ and $C_{2}$ under (a) $V_{\text {in }}=25 \mathrm{~V}$; (b) $V_{\text {in }}=35 \mathrm{~V}$ and currents of the inductors $L_{X}$ and $L_{Y}$ under (c) $V_{\text {in }}=25 \mathrm{~V}, R_{0}=150 \Omega$ and (d) $V_{\text {in }}=35 \mathrm{~V}, R_{0}=250 \Omega$.

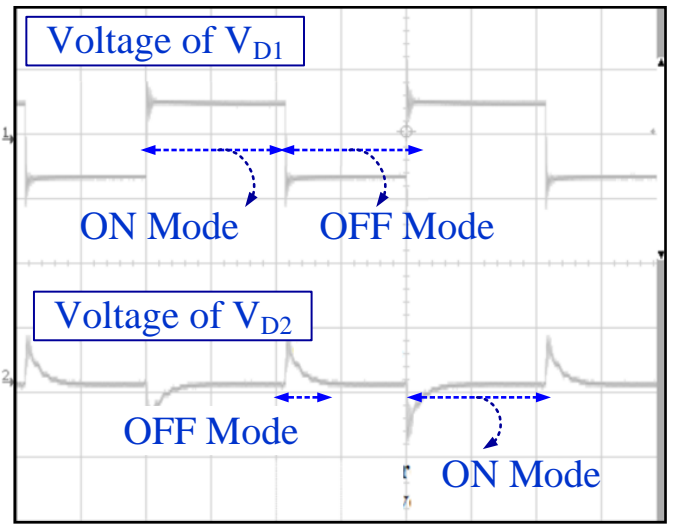

Figure 17. Oscillation domain of output DC voltage in the $50 \%$ duty cycle and switching frequency of $50 \mathrm{kHz}$.

In Figure 16a, under $25 \mathrm{~V}$ as the input voltage, by applying the proposed controller method, the output voltage was set to $120 \mathrm{~V}$. So, as expected based on Equation (30), half of this value was measured on the first capacitor and the second half of the proposed converter doubled this value on capacitor $C_{0}$. This test was undertaken on a $120 \Omega$ resistive load, so the voltages on the capacitors, especially the voltage on capacitor $C_{1}$, had fluctuations on switching times. The load value was set to $240 \Omega$ and the input voltage was increased to $35 \mathrm{~V}$ for Figure 16b, and as shown, these sudden ripples decreased. This event is normal because not only was the input voltage increased, but the output current was also a lower level in comparison with the first test. Figure 16c presents the current waveforms of the inductors for a $150 \Omega$ resistive load with $120 \mathrm{~V}$ and $25 \mathrm{~V}$ as the output and input voltages, respectively. As the results show, the current of the inductor $L_{Y}$ was less and the result confirmed Equations (34) and (35). Additionally, ripple values were reported of around 1.3 and $1.8 \mathrm{~A}$ for $L_{X}$ and $L_{Y}$, respectively, which is in agreement with the mathematical analysis presented in Table 1. Figure $16 \mathrm{~d}$ reports the results of the same process with a $250 \Omega$ resistive load, $35 \mathrm{~V}$ input, and $120 \mathrm{~V}$ output voltages. The obtained currents and ripple values confirmed the same equations mentioned for Figure 16c.

Figure 17 shows the status of the power diodes $D_{1}$ and $D_{2}$ and confirms the conductivity theory of these diodes in different work principles that was presented in Section 2.1 in $50 \%$ of the duty cycle. Based on this result, when the power diode $D_{1}$ is in ON mode, $D_{2}$ is in OFF mode and vice versa. A comparison was done in this part between the proposed PI controller and several other controllers in order to assess the performance of the projected structure. Different controllers have been investigated for DC-DC boost converters. The authors in [23] presented a fault tolerant-based DC-DC boost converter. This structure uses an extra Triode for Alternating Current (TRIAC) and an auxiliary power 
switch with a DC gain closed to the conventional boost converter. The optimal switching frequency of this converter was adjusted to $20 \mathrm{kHz}$ and the efficiency of the controller was calculated as around 87 percent for low power applications. In [24], a field-programmable gate array control technique was presented for non-isolated DC-DC converters. The basis of this controller was established on time and the current of the inductor and the robustness of the system was investigated. The controller worked in low switching frequencies around $15 \mathrm{kHz}$ and is suitable for high power applications. The inductor value was comparatively high and at the same time, several internal controller blocks worked to fix the output voltage. The study in [25] suggested a model-based state estimator approach for the DC-DC converter where the mathematical complexity and specifications of this converter such as switching frequency and inductor value were similar to the method presented in [24].

A PV-connected DC-DC boost converter using a LUENBERGER observer-based fault detection controller was presented in [26]. A deep mathematical approach was investigated in this study and the converter block worked as a part of the PV-based maximum power point tracking system. The converter's disadvantage is not applicable in high switching frequencies and is also proper for high power applications. Therefore, the IGBT is suggested for application instead of the power MOSFET. The authors in [27] presented a time-domain analysis of the state-space observer residual controller technique for interleaved DC-DC converters. The switching frequency was adjusted to $25 \mathrm{kHz}$. The total cost of the prototype was categorized in the medium to high range. Table 4 presents the general specifications of these controllers.

Table 4. Comparison of different controllers for DC-DC boost converters.

\begin{tabular}{ccccc}
\hline Reference & Controller & $\begin{array}{c}\text { Switching } \\
\text { Frequency }\end{array}$ & $\begin{array}{c}\text { Average Efficiency } \\
\text { (500 W) }\end{array}$ & Complexity \\
\hline$[23]$ & Capacitor voltage & $20 \mathrm{kHz}$ & 87 & Medium \\
{$[24]$} & Inductor current & $15 \mathrm{kHz}$ & 85 & Medium \\
{$[25]$} & State estimation & $10-20 \mathrm{kHz}$ & 87 & Medium \\
{$[26]$} & LUENBERGER observer & $10 \mathrm{kHz}$ & 85 & High \\
{$[27]$} & Linear observer & $25 \mathrm{kHz}$ & 90 & High \\
Proposed & PI & $50 \mathrm{kHz}$ & 91.5 & Medium \\
\hline
\end{tabular}

Figure 18 presents the efficiency curves for the presented controllers in Table 4 versus the output power. As can be seen, the performance of the proposed PI controller is considerable, especially in low powers. It can be interpreted based on all facts presented in Table 2. Based on less power MOSFET numbers in the converter's structure and good performance of the proposed PI controller to $350 \mathrm{~W}$, it had the highest efficiency. The performance of the linear observer acts in a similar way to the proposed controller for 350 to 500 power range.

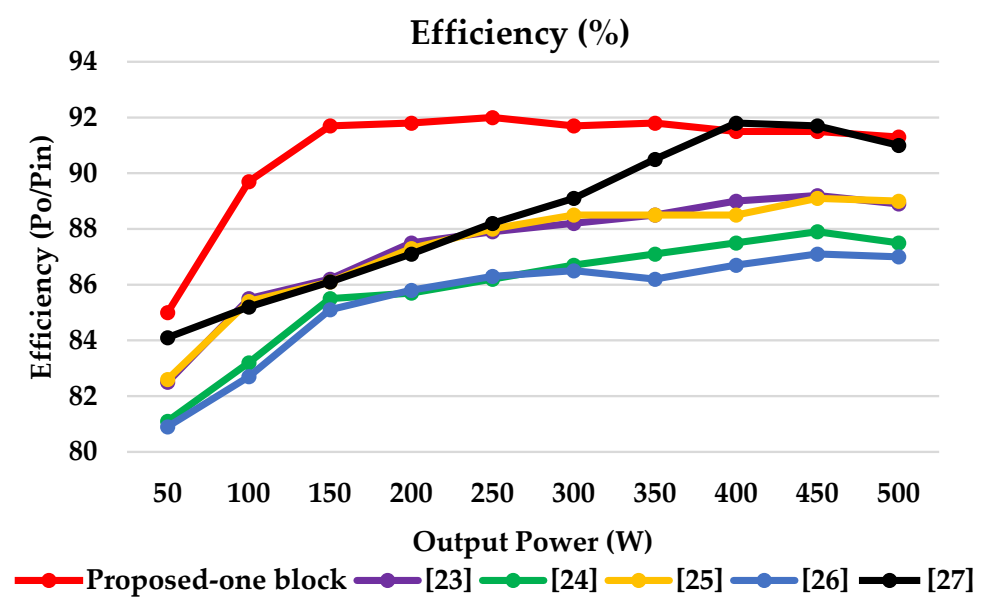

Figure 18. Efficiency comparison for different controllers for maximum power point tracking of DC-DC boost converter-based. 


\section{Conclusions}

This study presents a high gain step-up converter with a simple and cheap controller based on small signal analysis and steady space matrixes. In comparison with the conventional boost converter, the proposed converter uses two additional power diodes, a capacitor, and an inductor. However, the voltage gain of the projected converter is considerable and acts as a cascaded step-up converter. Furthermore, by considering that the topology has only one power switch and in any time interval only two diodes will be in the structure, it presents the same values of the losses in comparison with the cascaded converter by considering the switching, dynamic, and frequency losses. For the controller design, the topology was examined in two ON and OFF states of the switch. So, among all of the equations, the optimal equation that can present a relation between the output voltage and current derivation of the second inductor was selected. The controller was investigated through this equation and the simulation and experimental results showed the robust and stable working conditions for the proposed controller.

A group of simulations was undertaken in MATLAB/SIMULINK 2017a and the results confirmed the theoretical and mathematical analysis. Simulations were done for different values of the input voltages and output loads to generate the different voltages by the PV panels based on the irradiance and temperature. Therefore, a good controller should present stable and fixed DC voltages for the different values of this input source. Additionally, the stability of the structure and controller is important when different values of loads are entered at the output side of the structure. The results showed that for $24 \mathrm{~V}$ and $50 \Omega$ as the output load, the controller can reach the fixed desired $120 \mathrm{~V}$ with around $0.12 \mathrm{~S}$, which is acceptable for a topology that will work for a long time. A laboratory scaled prototype was implemented. For a $24 \mathrm{~V}$ input source, since the simulation results give $93 \mathrm{~V}$ as the output voltage in $50 \%$ of duty cycles, the prototype can present around $92.5 \mathrm{~V}$, which is acceptable and confirms the theoretical analysis and simulation results. Working in lower switching frequencies will help to decrease the voltage and current stresses on power switches where a high gain application is necessary. As a suggestion, soft switching and snubber sub-structures can be utilized to decrease these stresses.

Author Contributions: D.G., P.K.M., P.S., involved for the development of the concept, software analysis and hardware implementation, J.B.H.-N. supervise the project and validated the outcomes and numerical scale of proof, editing and final formulation of the work for ensuring quality of the presentation. J.B.H.-N., P.S., E.H., A.N. involved to make the article for its final presentation and error free technical aspects. P.K.M. involved to provide the graphical solution for the better presentation of the obtained results. All authors were involved equally in the contribution to present this research activity in its current full article for the readers with correction, edition, and proof version for its quality presentation. All authors have read and agreed to the published version of the manuscript.

Funding: There were no sources of funding for this research activities.

Acknowledgments: Authors acknowledge the Center for Bioenergy and Green Engineering, Aalborg University, Esbjerg, Denmark for providing technical support and expertise to make the article for its quality in presentation and execution.

Conflicts of Interest: The authors declare no conflict of interest.

\section{References}

1. Sanjeevikumar, P.; Bhaskar, M.S.; Maroti, P.K.; Blaabjerg, F.; Fedák, V. An Original Transformer and Switched-Capacitor (T\&SC) Based Extension for DC-DC Boost Converter for High-Voltage/Low-Current Renewable Energy Applications: Hardware Implementation of New T\&SC Boost Converter. Energies 2018, 11, 783.

2. Kalaiarasi, N.; Sanjeevikumar, P.; Paramasivam, S.; Subhransusekhar, D.; Maroti, P.K. Maximum Power Point Tracking Implementation by Dspace Controller Integrated Through Z-source Inverter Using Particle Swarm Optimization Technique for Photovoltaic Applications. Appl. Sci. 2018, 8, 145.

3. Bhaskar, M.S.; Meraj, M.; Iqbal, A.; Padmanaban, S.; Maroti, P.K.; Alammari, R. High Gain Transformer-Less Double-Duty-Triple-Mode DC/DC Converter for DC Microgrid. IEEE Access 2019, 7, 36353-36370. [CrossRef] 
4. Maroti, P.K.; Al-Ammari, R.; Bhaskar, M.S.; Meraj, M.; Iqbal, A.; Sanjeevikumar, P.; Rahman, S. A Novel High Gain Three-State Switching Hybrid Boost Converter for DC Microgrid Applications. IET Power Electron. 2019, 12, 2741-2750. [CrossRef]

5. Bayrak, G.; Ghaderi, D. An improved step-up converter with a developed real-timefuzzy-based MPPT controller for PV-based residential applications. Int. Trans. Electr. Energy Syst. 2019, 29, e12140. [CrossRef]

6. Ghaderi, D.; Bayrak, G. A Novel Step-Up Power Converter Configuration for Solar Energy Application. Elektron. Ir Elektrotechnika 2019, 25, 50-55. [CrossRef]

7. Li, W.; He, X. Review of nonisolated high-step-up dc/dc converters in photovoltaic grid-connected applications. IEEE Trans. Ind. Electron. 2011, 58, 1239-1250. [CrossRef]

8. Maroti, P.K.; Al-Ammari, R.; Bhaskar, M.S.; Meraj, M.; Iqbal, A.; Sanjeevikumar, P. A New Tri-Switching State Non-Isolated High Gain DC-DC Boost Converter for Microgrid Application. IET Power Electron. 2019, 12, 2741-2750. [CrossRef]

9. Yang, L.S.; Liang, T.J.; Lee, H.C.; Chen, J.F. Novel high step-up DC-DC converter with coupled-inductor and voltage-doubler circuits. IEEE Trans. Ind. Electron. 2011, 58, 4196-4206. [CrossRef]

10. Khalilzadeh, M.; Abbaszadeh, K. Non-isolated high step-up DC-DC converter based on coupled inductor with reduced voltage stress. IET Power Electron. 2015, 8, 2184-2194. [CrossRef]

11. Yazdani, M.R.; Alirezaei, M. Improved soft-switching boost converter with coupled-inductor using passive EMI cancellation method. EPE J. 2017, 27, 178-187. [CrossRef]

12. Muhammad, M.; Armstrong, M.; MElgendy, M.A. A nonisolated interleaved boost converter for high-voltage gain applications. IEEE J. Emerg. Sel. Top. Power Electron. 2016, 4, 352-362. [CrossRef]

13. Ching, T.K.; Huang, C.C.; Shih, W.Y. A high step up converter with a voltage multiplier module for a photovoltaic system. IEEE Trans. Power Electron. 2012, 28, 3047-3057.

14. Tseng, K.C.; Lin, J.T.; Huang, C.C. High step-up converter with three-winding coupled inductor for fuel cell energy source applications. IEEE Trans Power Electron. 2015, 30, 574581. [CrossRef]

15. Park, K.B. Partial series resonant coupled-inductor boost converter for high step-up DCDC applications. EPE J. 2018, 28, 1427. [CrossRef]

16. Wn, B.; Li, S.; Smedley, K.M. A new sngle switch isolated high gain hybrid boosting converter. IEEE Trans. Ind. Electron. 2016, 63, 4978-4988.

17. Sathyan, S.; Suryawanshi, H.M.; Singh, B.; Chakraborty, C.; Verma, V.; Ballal, M.S. Zvs-zcs high voltage gain integrated boost converter for dc microgrid. IEEE Trans. Ind. Electron. 2016, 63, 6898-6908. [CrossRef]

18. Ghaderi, D.; Celebi, M.; Minaz, M.R.; Toren, M. Efficiency Improvement for a DC-DC Quadratic Power Boost Converter by Applying a Switch Turn-off Lossless Snubber Structure Based on Zero Voltage Switching. Elektron. Elektrotechnika 2018, 24. [CrossRef]

19. Maroti, P.K.; Padmanaban, S.; Wheeler, P.; Blaabjerg, F.; Rivera, M. Modified boost with switched inductor different configurational structures for DC-DC converter for renewable application. In Proceedings of the 2017 IEEE Southern Power Electronics Conference (SPEC), Puerto Varas, Chile, 4-7 December 2017; pp. 1-6.

20. Maroti, P.K.; Padmanaban, S.; Blaabjerg, F.; Martirano, L.; Siano, P. A novel multilevel high gain modified SEPIC DC-to-DC converter for high voltage/low current renewable energy applications. In Proceedings of the 2018 IEEE 12th International Conference on Compatibility, Power Electronics and Power Engineering (CPE-POWERENG 2018), Doha, Qatar, 10-12 April 2018; pp. 1-6.

21. Ogata, K. PTR Upper Saddle River. In Modern Control Engineering; Prentice-Hall: Upper Saddle River, NJ, USA, 2001.

22. Nejad, M.L.; Poorali, B.; Adib, E.; Birjandi, A.A.M. New cascade boost converter with reduced losses. IET Power Electron. 2016, 9, 1213-1219. [CrossRef]

23. Huangfu, Y.; Zhuo, S.; Chen, F.; Pang, S. Evaluation and fault tolerant control of a floating interleaved boost converter for fuel cell systems. In Proceedings of the 2016 IEEE Industry Applications Society Annual Meeting, Portland, OR, USA, 2-6 October 2016; pp. 1-7.

24. Shahbazi, M.; Jamshidpour, E.; Poure, P.; Saadate, S.; Zolghadri, M.R. Open-and short-circuit switch fault diagnosis for nonisolated DC-DC converters using field programmable gate array. IEEE Trans. Ind. Electron. 2013, 60, 4136-4146. [CrossRef]

25. Poon, J.; Jain, P.; Konstantakopoulos, I.C.; Spanos, C.; Panda, S.K.; Sanders, S.R. Model-based fault detection and identification for switching power converters. IEEE Trans. Power Electron. 2017, 32, 1419-1430. [CrossRef] 
26. Jain, P.; Jian, L.; Poon, J.; Spanos, C.; Sanders, S.R.; Xu, J.X.; Panda, S.K. A luenberger observer-based fault detection and identification scheme for photovoltaic DC-DC converters. In Proceedings of the IECON 2017-43rd Annual Conference of the IEEE Industrial Electronics Society, Beijing, China, 29 October-1 November 2017; pp. 5015-5020.

27. Wassinger, N.; Penovi, E.; Retegui, R.G.; Maestri, S. Open-circuit fault identification method for interleaved converters based on timedomain analysis of the state observer residual. IEEE Trans. Power Electron. 2019, 34, 3740-3749. [CrossRef]

(C) 2019 by the authors. Licensee MDPI, Basel, Switzerland. This article is an open access article distributed under the terms and conditions of the Creative Commons Attribution (CC BY) license (http://creativecommons.org/licenses/by/4.0/). 